\title{
PARTNER SEARCH AND DEMOGRAPHICS: THE MARRIAGE SQUEEZE IN INDIA
}

\author{
ANJA SAUTMANN \\ August 2011 \\ (first version December 2009) \\ Brown University \\ anja_sautmann@brown.edu
}

\begin{abstract}
If women marry younger than men, increased population growth causes a surplus of women in the marriage market. This paper introduces search frictions into a matching model with transferable utility and age-dependent match payoffs to study if this so-called marriage squeeze has caused a dowry "inflation" in India. Using data from Karnataka it is shown that the observed shifts in the age distributions and sex ratio of unmarried men and women during the marriage squeeze lead to higher dowries conditional on the partners' ages. A GMM estimate of the model parameters suggests that average dowries have increased as well. (JEL C78, J12, O18)
\end{abstract}

This paper is based on a chapter of my dissertation. I would like to thank Debraj Ray, Ricardo Lagos, Ahu Gemici, and Matt Wiswall for many in-depth discussions. I am grateful to Attila Ambrus, Andrew Caplin, Eugene Choo, Raquel Fernández, Chris Flinn, Andrew Foster, Maria Eugenia Garibotti, Alessandro Lizzeri, Sriniketh Nagavarapu, Efe Ok, Pietro Ortoleva, Mark Pitt, Ennio Stacchetti, and the participants of a number of seminars for very helpful comments. Vijayendra Rao generously gave me access to the NCAER data. 
Marriage patterns in India have changed substantially in the course of the $20^{\text {th }}$ century. The mean marriage age of women has risen from 13 years in 1911 to 19 years in 1991, while that of men increased by four years during the same period, reducing the average age difference between husband and wife from seven to under five years. This change has been attributed to the so-called "marriage squeeze": when women marry younger than men, higher population growth (higher birth rates and declining child mortality) leads to a surplus of women in the marriage market. To resolve this surplus, the age gap at marriage must decline.

A common theory argues that the marriage squeeze in India is responsible for the "inflation" in dowries, the marriage payments from the bride's family to the groom's: the squeeze causes a scarcity of husbands which pushes up the price of marriage for women (Caldwell et al. (1983); Bhat and Halli (1999); for an early discussion of the marriage squeeze in Economics and an application to Sweden see Bergstrom and Lam (1989a,b)). High dowries make raising a daughter a considerable financial burden, and they have accordingly been blamed for infanticide and neglect of female children, sex selective abortion, and mistreatment of newly married women in attempts to extract more money from their parents (see e.g. Prasad (1994), Sev'er (2008)). The "monster of modern dowry" (Srinivas (1984)) persists despite state-level bans as early as 1939 and the national Dowry Prohibition Act from 1961. ${ }^{1}$

Anderson (2007b) uses a typical (frictionless) matching model with transfers and age preferences to study the effects of a marriage squeeze caused by a one-time population shock. She shows that any change in the marriage age gap must here be accompanied

\footnotetext{
${ }^{1}$ For an account of the difficulties to resist participating in dowry, see Kishwar (2006). She writes that her "stand [to boycott dowry] was viewed with respect, even appreciation. But it did not lead anyone (except my two brothers) to refrain from taking (or giving) dowry, even thought some were apologetic about their compulsions" (p.268/9). Caplan (1984) observes that dowry prohibition had no effect except to make sure that "the custom remains out of sight and in the realm of partial secrecy" (p.219). Billig (1992) notes that "the overwhelming opinion" about dowry was "that it is something that the parents of a girl (...) are forced to do in spite of the economic hardship that it entails" (p.210).
} 
by falling dowries: women will be willing to delay marriage, and marry at a smaller age difference, only if they have to pay less in return. However, marriage age cannot change in this model in response to a permanent rise in the number of men and women, as would be caused for example by higher population growth. Instead, dowries must increase to the point where women are indifferent between marrying and remaining single, and the supernumerary women in every generation remain unmarried. In other words, the frictionless marriage model fully places the adjustment burden on prices, leading only to higher rates of spinsterhood. ${ }^{2}$ Yet the Indian census documents that marriage rates in India are virtually unchanged since the early 20th century, while the marriage age gap has fallen substantially. An analysis of the effect of increased population growth on the marriage market must therefore account for the decreasing marriage age gap.

This paper builds a two-sided search model to reexamine the effects of the marriage squeeze on marriage ages and dowries. The framework captures some key features of the marriage market: the numbers of unmarried men and women at each age depend on demographic parameters, and market participants have preferences over age and become older during their search for a partner. Utility is transferable, so that the marriage surplus can be redistributed via a dowry payment. The presence of frictions means that a tight market increases both the duration of search and the threat of becoming too old before finding a partner. Demographic pressure can therefore raise willingness to pay while at the same time drawing out the search process and increasing average marriage age. ${ }^{3}$

\footnotetext{
${ }^{2}$ See (Sautmann (2010) for a detailed argument. The intuition is that population growth causes a surplus of women in every generation. For each woman who marries later than optimal, there is always another woman at the ideal age available, and this cannot be a stable outcome.

${ }^{3}$ It should be noted that the approach taken here is not directly comparable with the frictionless model. In Anderson (2007b), the one-time population shock as well as the dowry function are part of the same equilibrium. By contrast, I will compare (constant) marriage behavior and dowries between steady-state equilibria for different demographic parameters.
} 
It will be shown that the model can accommodate marriage age change and dowry inflation at once. Specifically, starting from one steady state, raising the rate of growth in the number of births can lead to a new steady state with higher average dowry and a smaller age gap. This effect need not be driven by marriage strategies: even if, for example, women are willing to marry earlier in the new steady state, the scarcity of husbands can cause their search to last longer and their marriage age to rise.

Based on the model I can compare dowry and marriage ages between different equilibria. Since there is now a stochastic element to the matching process, two aspects of dowry inflation must be distinguished, namely, increases in payments conditional on the age of the partners and increases in average payments. The latter is a good measure of the strain imposed by high dowries if households are e.g. subject to liquidity constraints, but it cannot separate changes in match-specific transfers from changes in what matches are observed. The former more accurately captures the true "price" change by looking at matches of a given quality (i.e. at given ages). Using census data for the Indian state of Mysore (today Karnataka) from before and after the marriage squeeze, along with marriage data from the National Family Health Survey, I demonstrate that the observed changes in the age distributions imply increases in dowries conditional on partners' ages, caused by a relative drop in the value of search for women. In addition, a GMM estimation of the marriage payoff function in this model shows that demographic growth did have an inflating effect on average marriage transfers, and at the same time led to a decrease in the age gap at marriage. A key assumption for these comparisons is that the underlying marriage age preferences have not substantially changed during the marriage squeeze, and in section 4.1 I argue that many of the potential drivers of marriage age preferences - in particular fertility, education levels, and economic growth have been relatively stable up to the end of the squeeze in the 1970s.

The next section gives a detailed account of the literature on marriage squeeze and dowry inflation. Section 2 describes the model and defines the equilibrium. Three examples provide intuition for the forces that drive changes to dowries and average marriage ages, and show that a shrinking age gap and rising dowries can occur together (section 3). Section 4 compares conditional dowries between equilibria with different equilibrium age distributions, 
Figure 1. Population growth rate in India $(\square)$ and Karnataka (•), data from Sekher et al. (2001), Census of India.

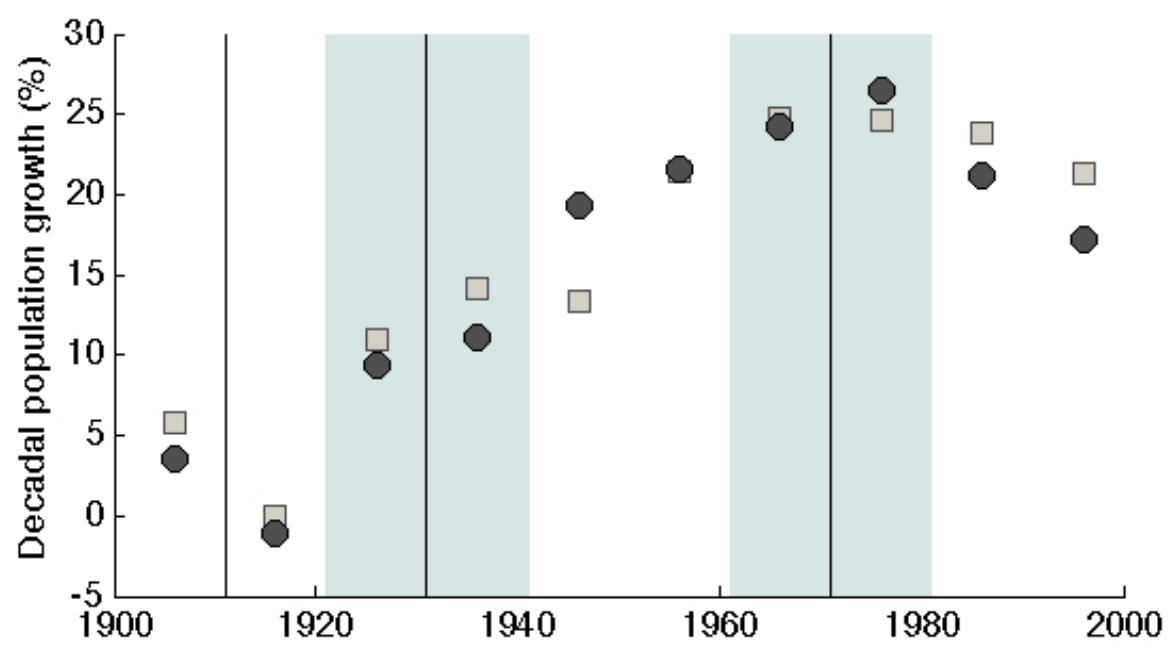

and then applies the comparative statics results to the actual demographic changes in Karnataka. Section 5 describes the estimation strategy for average dowries and marriage ages and presents the results, and section 6 concludes.

\section{Marriage Squeeze and Dowry Inflation}

Population Growth and Marriage Squeeze. A marriage squeeze is the result of an acceleration of population growth. Figure 1 depicts the decadal population growth rate in India and in Karnataka from 1901 to 2001 at the midpoints between census years (1901, 1911, etc.). After a period of famine, population growth picked up for the first time in 1901-11 (Dyson et al. (2004), p.22). The country experienced terrible losses from the influenza epidemic in 1918 (ibid.), leading to a population decrease in 1911-21, but in the next few decades the growth rate reached over $10 \%$ and eventually sped up to nearly $25 \%$ in 1961-81. Fertility declines finally reversed the trend in the 1980s. Correspondingly, 1920-1980 can be thought of as the main period of the marriage squeeze, with the greatest shifts in the marriage market probably between the 1930s and 1960s.

Even though families universally complained about a growing scarcity of grooms and strong competition among girls (e.g. Epstein (1973), Caplan (1984), Bloch and Rao (2002)), 
the existence of a marriage squeeze was initially doubted, because India had an overall shortage of women for much of the last century. Unlike in most other parts of the world, the male-female sex ratio in South Asia exceeds one due to higher female mortality than elsewhere (Amartya Sen's "missing women", see also Coale (1991) and Visaria (1969)).

However, conditions in the marriage market depend on the ratio of men and women at the relevant ages who are actually available for marriage. If there is high population growth and women marry at younger ages, the sex ratio at marriage age can still favor men. Several studies in India found that there were in fact more women than men at prime marriage age in the areas under scrutiny (Caldwell et al. (1983), Billig (1991), Rao (1993)). With reference to India's demographics today, Tertilt and Neelakantan (2008) calculate that a population growth rate of $1.43 \%$ "adds" 14 women to the overall sex ratio of 95 women per 100 men (assuming five years age difference at marriage). Holding marriage age fixed, it can be shown that the sex ratio of single men and women in India rapidly deteriorated during the $20^{\text {th }}$ century. Bhat and Halli (1999) calculate an adjusted sex ratio index at the ages at which men and women used to marry in 1911 and show that it dropped from 100 in 1911 to a low of 53.4 men per 100 women in $1971 .^{4}$

The marriage squeeze is directly linked with the age difference at marriage. A surplus of women caused by demographic growth can only be accommodated if the age gap shrinks; otherwise some women must remain unmarried. In other words, the marriage squeeze originates in a preference for a positive age difference at marriage, but to resolve the surplus of women the marriage age gap must fall. Conversely, if there is nonzero population growth the age gap at marriage can decrease without a change in marriage rates only if the growth rate accelerates, so that consecutive age cohorts become larger. Table 1 assembles different estimates of the average marriage ages for India and Karnataka, along with the percentage of never married men and women at ages 45-54. It shows that the proportion of women

\footnotetext{
${ }^{4}$ They do account for the possibility of widower remarriage, which makes the squeeze more pronounced.
} 
TABle 1. Marriage Squeeze Indicators.

\begin{tabular}{|c|c|c|c|c|c|c|c|c|c|c|c|}
\hline & \multicolumn{9}{|c|}{ Mean age at marriage and average age gap } & \multirow{2}{*}{\multicolumn{2}{|c|}{$\frac{\% \text { never married }}{\text { India }(4)}$}} \\
\hline & \multicolumn{3}{|c|}{ India $(1)$} & \multicolumn{3}{|c|}{ Mysore/Karnataka (2) } & \multicolumn{3}{|c|}{ Karnataka (3) } & & \\
\hline & men & women & gap & men & women & gap & men & women & gap & men & women \\
\hline 1911 & 19.8 & 12.9 & 6.9 & 24.24 & 15.21 & {$[9.03]$} & & & & 4.2 & 0.9 \\
\hline 1921 & 20.2 & 13.3 & 6.9 & 24.92 & 15.22 & {$[9.70]$} & {$[22.98]$} & 14.47 & 8.51 & 4.1 & 1.1 \\
\hline 1931 & 19.0 & 12.9 & 6.1 & 23.83 & 14.55 & {$[9.28]$} & & & & 3.8 & 0.8 \\
\hline 1951 & 20.6 & 15.2 & 5.4 & 25.48 & 16.20 & {$[9.28]$} & & & & 3.7 & 1.2 \\
\hline 1961 & 21.6 & 15.9 & 5.7 & 24.40 & 16.32 & [8.08] & & & & 3.3 & 0.5 \\
\hline 1971 & 22.4 & 17.2 & 5.2 & 25.24 & 17.79 & {$[7.45]$} & & & & 2.6 & 0.5 \\
\hline 1981 & 23.3 & 18.3 & 5.0 & 25.88 & 19.20 & [6.68] & [25.04] & 18.45 & 6.59 & 2.2 & 0.5 \\
\hline 1991 & 23.8 & 19.0 & 4.8 & 26.22 & 20.15 & {$[6.07]$} & & & & 2.5 & 0.7 \\
\hline
\end{tabular}

(1), (4): Bhat and Halli (1999), table 3; singulate mean age at marriage (SMAM) and unmarried at ages 45-54. (2) Agarwala (1957), table 3, synthetic census cohorts (1911-51), Mysore; Sekher et al. (2001), table 7 (1961-91). (3) Banerjee (1998), table 5, SMAM, geographic equivalent of today's Karnataka. - Values in square brackets calculated. 1941 marriage data not collected due to WWII.

who remained permanently unmarried was stable over time, but the average age difference between husband and wife at first marriage fell by about two years. ${ }^{5}$

Dowry and Dowry Inflation. Dowry in India today is an almost universal phenomenon (93-94\% of marriages, Anderson (2007a)), with payments often well above the typical annual income (ibid., Zachariah (1984), Kodoth (2008)), despite the Dowry Prohibition Act. Anthropological and ethnographic research reports that individual payments have greatly increased $^{6}$, and what was originally an exclusive practice of high castes in the North gradually spread to the whole country and replaced the former dominant custom of brideprice (Caplan

\footnotetext{
${ }^{5}$ As an aside, note that the unusually high initial age gap at marriage for India is presumably only possible because India actually had and has "missing women" - otherwise the younger cohorts would be too large for all women to marry.

${ }^{6}$ Many of these accounts are anecdotal in nature. For example, Billig (1992) quotes a "prosperous Syrian Christian man in his mid-50's" from Kerala, who says that when he 
(1984), Srinivas (1984), Billig (1991, 1992), Menski (1998), Palriwala (2006), Sharma (2006), Guttentag and Secord (1983), Singh (2004), Bhat and Halli (1999), Caldwell et al. (1983); see last two for further sources). Caldwell et al. (1983) chronicle this progress in Karnataka, starting in Madras in the 1930s, with the first dowries paid in their rural study area in 1965.

The same authors also document the great importance of a girl's early marriage for a family's social status. Families' "overwhelming fear is that no husband may be found" if a girl is still unmarried at 19 or 20 (p. 351). Along with others they emphasize the age of the bride as a factor for the dowry (Kodoth (2008), Zachariah (1984)).

Many theories ultimately attribute the inflation of dowries to economic growth and rising wealth. The availability of men with higher and more stable incomes, the push to "marry up" by newly affluent members of low castes, or the increasing willingness and ability to pay for status by emulating customs of higher castes ("Sanskritization") may have inflated the prices of husbands (Rajaraman (2006), Anderson (2003), Srinivas (1952)). Dowries may also serve as a form of pre-mortem bequest which rises with the wealth of the father, given that women until recently had no inheritance rights (Botticini and Siow (2003), Zhang and Chan (1999), Goody (1973), see e.g. Sharma (2006) on women's property rights). However, while these causes certainly play a role, they cannot fully explain the time frame and geographic spread of dowry inflation across India. The bequest interpretation is at odds with the fact that the bride has often little control over her dowry and that the part traditionally considered hers, the stridhana, did not change over time (Bhat and Halli (1999)). ${ }^{7}$ Hypergamy (marrying into a higher caste) is common in the North, but South India is isogamous (Srinivas (1984)). ${ }^{8}$ But most importantly, India's per capita national income was stagnant (or possibly even falling) between 1910 and 1959, with moderate growth only from 1960 on (Sivasubramonian (2000), was young "a doctor would cost about 20000 rupees", but would now be more than 800000 rupees (about \$48000).

${ }^{7}$ The dowry is also often not given willingly. Bloch and Rao (2002) put it bluntly when they describe dowry violence as a "bargaining instrument". Zachariah (1984) observes that $7 \%$ of marriages in his sample were delayed because of insufficient payment.

${ }^{8}$ Srinivas makes the direct link with dowry, stating that "in the isogamous South, modern dowry is really a totally new development." 
Maddison (1983)). Yet the existing evidence seems to indicate that the increase in (net) dowries started around 1920 and leveled out around the time economic growth began. In Rao's (1993) study in Karnataka, dowries are significantly correlated with year of marriage, and after controlling for partners' characteristics and market conditions, dowries increase on average by ₹258 annually over the 55 years from 1923 to 1978, with most of the gain before 1950 (Edlund (2006)). Paul (1986) finds a more than twentyfold increase in real dowry among families in Delhi from 1920 to 1969, but from 1970-79 onwards, dowries began to fall in real terms, even though the nominal amounts tripled. This pattern coincides with the time frame of the marriage squeeze.

Logan and Arunachalam (2008) challenge the marriage squeeze hypothesis from a different angle. They argue that the perception of systematically increasing dowries in South Asia may be mistaken: using two data sets from India they find no upwards time trend in dowries. One of the data sets covers a period when demographic pressure already began to ease, from 1970 to 1994. However, they also re-analyze the Rao (1993) data set and find no trend.

It is therefore possible that there was no average increase in dowries, and that husbands' prices rose only conditional on quality, or perhaps that the inflation of dowries was purely subjective. Another reason for the contradiction may be the difficulty of measuring dowry payments and consequently of interpreting the data. A data set from Karnataka collected by the National Council of Applied Economic Research under the supervision of Sonalde Desai and Vijayendra Rao exemplifies this. Dowries were measured as the real net value of all transfers and gifts related to the marriage. Out of a sample of 601 , only for 375 a dowry sum could be calculated, and only in 33 cases husband and wife agree on it. The average net dowry was ₹16,515, but wives claim to have paid on average over ₹16,000 more than what husbands say they received. At the same time, recorded payments vary between -800,000 and over 3 million rupees.

This illustrates a general problem: eliciting accurate sums for a large sample size is very difficult, not only because dowries are illegal, but also because they are often given in kind and in several installments, intermingled with gifts and other transfers, and the data must be collected retrospectively. Even though most researchers agree that dowries have increased, 
the existing quantitative evidence is thus not entirely conclusive. This paper studies the connection between demographics and dowries, but in doing so it also contributes to the larger question of whether dowry inflation has actually taken place.

\section{The Search Model and Marriage Market Equilibrium}

The marriage market model I propose is a search model with transferable utility. Search frictions have important implications for the effects of a marriage squeeze, because they can delay of marriage for women when increased demographic growth reduces the relative number of unmarried men. Transferable utility means that match surplus can be redistributed through payments at marriage, the dowry. The model assumes that men and women, or perhaps more accurately, families with a son or daughter at marriageable age, each search for a partner. They meet according to a probability distribution and then decide if they want to get married. A couple will marry whenever their joint surplus is greater than the sum of their outside options, and the outside options are given by the prospect of meeting another partner at a later date.

In a steady state, the distribution of singles at different ages, and therefore the meeting probabilities that determine the outside options of all market participants, are constant in every period. The age composition of the unmarried population is modeled as the explicit result of entry by young cohorts, and of exit from marriage and mortality, where the growth rate of births, birth sex ratios, and mortality rates are exogenous parameters. ${ }^{9}$

Unlike in most search models, where heterogeneity comes from a characteristic that has a population distribution, the marriage payoff, and consequently the agent's outside options, is assumed to depend on age, and can therefore change over time for the individual market participant. Ljungqvist and Sargent (1998) and Coles and Masters (2000) introduced a similar kind of "aging" into search in the context of labor markets, by assuming that unemployed workers gradually lose skills. The age-dependence of the marriage payoff function can be thought of as a summary of the couple's and their families' preferences over age at marriage,

\footnotetext{
${ }^{9}$ In labor market search models, a steady state in the market distribution of workers and jobs is usually achieved by assuming entry through exogenous match dissolution rates.
} 
bringing together an array of motives from fertility and health concerns to labor market status and the parents' retirement plans. It is of course a simplification to assume that marriage payoffs depend only on the age of the partners, but age preferences can perhaps be thought of as "orthogonal" to preferences over other (time-invariant) characteristics. The market described here could then be seen as the outcome of many stratified submarkets, each reflecting assortative matching according to characteristics like wealth and beauty. Within those submarkets, individuals will only take their own and their partner's age into account.

\subsection{Population Development in Steady-State}

As a first step in building the model I derive the age distributions of unmarried men and women, or the singles distribution for short, starting from absolute population numbers. It will be shown that the age distribution of singles can attain a steady state, even though absolute numbers are subject to change in a world with population growth. Let $i=1, \ldots, I$ be the age of women, and $j=1, \ldots, J$ that of men in the marriage market. Age one is normalized as the first period after entry into the marriage market. For convenience, we will allow for an age gap at market entry, denoted by $a$ : if the market entry age is for example ten years for women, but fourteen for men, and the time period is a year, a equals four.

The size of the female population at time $t$ is $W_{t}$, and $W_{i, t}$ the measure of women at age $i$, with the equivalent $M_{t}$ and $M_{j, t}$ for men. Let $s=\left(s_{2}, \ldots, s_{I}\right)$ denote the survival rates for the female population, so that $s_{i}$ describes the proportion of women at $i-1$ who are still alive at $i$. The transition rates of the male population are $z=\left(z_{2}, \ldots, z_{J}\right)$. The number of men and women born grows at rate $g$ between two consecutive birth cohorts. Assuming that survival up to entering the marriage market is constant, this implies $W_{1, t+1}=(1+g) W_{1, t}$ and $M_{i, t+1}=(1+g) M_{1, t}$. Note that I am not modeling the source of the increase in cohort size. The interaction of mortality changes and fertility decisions as determinants of the overall rate of population growth is fairly complex; for example, a sustained decline in infant mortality can lead to a more rapid increase in the size of consecutive cohorts at entry into the marriage 
market, but may induce a lower fertility rate in response. I summarize these factors simply as an exogenous change in $g .{ }^{10}$

Couples meet once every period and decide to marry based on the payoffs from their partnership versus the outside options that both of them have. Marriage decisions are captured by a matrix of marriage indicators:

$$
\mathrm{A}=\left(\begin{array}{ccc}
\alpha_{11} & \cdots & \alpha_{1 J} \\
\vdots & \ddots & \vdots \\
\alpha_{I 1} & \cdots & \alpha_{I J}
\end{array}\right)
$$

Upon meeting, a woman of age $i$ and a man of age $j$ choose to marry with probability $\alpha_{i j} \in[0,1]$. If they are indifferent between marrying and not marrying, $\alpha_{i j}$ may lie strictly between 0 and 1 . Each $\alpha_{i j}$ also describes the proportion of $(i, j)$ couples who marry. Married couples leave the market for good.

A single woman of age $i$ and a single man of age $j$ meet according to a probability distribution which depends on the current numbers of single men and women at all ages in the market. In fact, I assume that it depends on relative numbers only, namely the singles distribution $d_{t}=\left(w_{t}, m_{t}, r_{t}\right)$. The scalar $r_{t}$ is the singles sex ratio $\frac{M_{t}}{W_{t}}$. The vectors $w_{t}$ and $m_{t}$ describe the age distributions for men and women, with $w_{i t}$ and $m_{j t}$ as the proportion of age- $i$ women in the female population and age- $j$ men in the male population, respectively.

\footnotetext{
${ }^{10}$ Ideally, population growth would be endogenous to the model since fertility likely depends on marriage age. However, the effect of an "involuntary" change in marriage age (due to adverse conditions in the marriage market) on fertility choices is likely complex and seems not well-studied (but see Dommaraju (2008)). At the same time, assume that there is a more comprehensive model in which higher population growth from lower mortality affects marriage age, which then feeds back into fertility and thus population growth: any two equilibria in this model with an (endogenously) low growth rate before the change and a high growth rate after will coincide with two equilibria in the present model in which $g$ is chosen as exogenously either low or high.
} 
The functions $P_{i j}(d)$ and $Q_{j i}(d)$ describe the probability of an age- $i$ woman meeting an age- $j$ man and that of an age- $j$ man meeting an age- $i$ woman, respectively, given a singles distribution $d$. It must hold that $\sum_{i=1}^{I} Q_{j i} \leq 1$ and $\sum_{j=1}^{J} P_{i j} \leq 1$.

\subsection{From Absolute to Relative Demographics}

The singles distribution $d_{t}$, the variable which determines the meeting probabilities and therefore governs search frictions, can under certain conditions attain a steady state. Suppose for the moment that individual marriage strategies are fixed. Starting from absolute numbers, we would like to take the birth sex ratio within a cohort, $b$, the growth rate of births $g$, transition vectors $s$ and $z$, and the age gap $a$ as given, and find a singles distribution that replicates itself in every period. In what follows all expressions are derived for the women's side of the market, and the equivalent expression for the men's side is stated without derivations.

First, define the market 'staying rate' from age $i$ to age $i+1$ in the next period as

$$
\varphi_{i, t}=s_{i+1}\left(1-\sum_{k=1}^{J} \alpha_{i, k} P_{i j}\left(d_{t}\right)\right)
$$

This is the proportion of women at age $i$ in $t$ who do not marry, multiplied by the survival rate; in other words, these are the women who are still in the market in $t+1$, now at age $i+1$. Equivalently, the staying rate for men at age $j$ is

$$
\psi_{j, t}=z_{j+1}\left(1-\sum_{k=1}^{I} \alpha_{k, j} Q_{j i}\left(d_{t}\right)\right) .
$$

The number of single women at each age in period $t, W_{i, t}$, can now be expressed in terms of the $W_{i, t-1}$, and iterating over $t$ produces the vector of female populations at ages $1, \ldots, I$ :

$$
\left(\begin{array}{r}
(1+g)^{I} W_{1, t-I} \\
\varphi_{1, t-1}(1+g)^{I-1} W_{1, t-I} \\
\varphi_{2, t-1} \varphi_{1, t-2}(1+g)^{I-2} W_{1, t-I} \\
\vdots \\
\left(\prod_{k=1}^{I-1} \varphi_{I-k, t-k}\right) \cdot(1+g) W_{1, t-I}
\end{array}\right)
$$


From here on, applying the iteration further will only change the time indices on the $\varphi_{i}$ and take the $(1+g)$ term to higher powers. Summing up over the vector entries yields the total female population

$W_{t}=\left[1+\frac{\varphi_{1, t-1}}{(1+g)}+\frac{\varphi_{2, t-1} \varphi_{1, t-2}}{(1+g)^{2}}+\ldots+\prod_{k=1}^{I-1}\left(\frac{\varphi_{I-k, t-k}}{(1+g)}\right)\right](1+g)^{I} W_{1, t-I} \equiv \Phi_{t}(1+g)^{I} W_{1, t-I}$.

Deriving the male population in the same manner gives

$M_{t}=\left[1+\frac{\psi_{1, t-1}}{(1+g)}+\frac{\psi_{2, t-1} \psi_{1, t-2}}{(1+g)^{2}}+\ldots+\prod_{k=1}^{J-1}\left(\frac{\psi_{J-k, t-k}}{(1+g)}\right)\right](1+g)^{J} M_{1, t-J} \equiv \Psi_{t}(1+g)^{J} M_{1, t-J}$.

Using that $W_{i, t+1}=\varphi_{i, t} W_{i-1, t}$, the age proportions of the single female population can be written iteratively as

$$
w_{i, t+1}=\varphi_{i-1, t} \frac{W_{i-1, t}}{W_{t+1}}=\varphi_{i-1, t} \frac{W_{t}}{W_{t+1}} w_{i-1, t}=\frac{\varphi_{i-1, t}}{(1+g)} \frac{\Phi_{t}}{\Phi_{t+1}} w_{i-1, t} .
$$

for $i=2, \ldots I$. A steady state of the singles distribution is characterized by a constant vector $d$, so that $\Phi$ and $\Psi$ remain unchanged over time. The equations for the age proportions become

$$
\begin{aligned}
w_{i} & =\frac{\varphi_{i-1}}{(1+g)} w_{i-1} \\
m_{j} & =\frac{\psi_{j-1}}{(1+g)} m_{j-1}
\end{aligned}
$$

Using that the terms have to add up to one and substituting $\prod_{k=1}^{i-1} \frac{\varphi_{k}}{(1+g)} w_{1}$ for $w_{i}$ yields

$$
\begin{aligned}
& w_{1}=\Phi^{-1}, \text { where } \Phi=\left\{1+\sum_{i=1}^{I-1}\left(\prod_{k=1}^{i} \frac{\varphi_{k}}{(1+g)}\right)\right\}, \text { and similarly } \\
& m_{1}=\Psi^{-1}, \text { where } \Psi=\left\{1+\sum_{j=1}^{J-1}\left(\prod_{k=1}^{j} \frac{\psi_{k}}{(1+g)}\right)\right\} .
\end{aligned}
$$

With stable population growth $g$, the relative sizes of age- 1 cohorts at any given time are determined by the age difference $a$ at entering the marriage market, survival rates until entry, and the sex ratio at birth. ${ }^{11}$ Letting $z_{0}$ and $s_{0}$ be the survival rates from birth to market

${ }^{11}$ Observe that the ratio at birth refers to boys and girls born in the same year, while the index $t$ refers to men and women entering the market in the same period. The age difference implies that these men and women are from different birth years. 
entry for men and women, the ratio of $M_{1, t}$ to $W_{1, t}$ is $\frac{z_{0}}{s_{0}} \frac{b}{(1+g)^{a}}$, and the singles sex ratio can be written as a function of $w_{1}$ and $m_{1}$ only:

$$
r=\frac{M_{t}}{W_{t}}=\frac{z_{0}}{s_{0}} \frac{b}{(1+g)^{a}} \frac{w_{1}}{m_{1}}
$$

The steady-state singles distribution $d$ is thus fully described by equations (2.1)-(2.4).

The following observations are simple, but useful for a better understanding of the age structure of the marriage market in steady state. First, note that with $g \geq 0$ each consecutive age group has a lower share in the overall population, since $w_{i} \geq w_{i+1}$. The inequality is strict if there is positive population growth. With only two age groups, for instance, the younger women are always in the majority. The most "equal" distribution is theoretically possible if $g=0$ and $w_{1}=w_{i}=\frac{1}{I}$, but this requires that no woman marries. This holds of

course equivalently for the men's age distribution $m$. Secondly, the sex ratio $\frac{M_{t}}{W_{t}}$ is inversely proportional to $\frac{m_{1}}{w_{1}}$. The basis for the singles sex ratio, namely the total population of men and women at marriageable age, is determined by exogenous demographic parameters, that is by population growth and mortality. Beyond that, a higher proportion of age-1 grooms means that men leave the marriage market faster. Similarly, a low $w_{1}$ means women marry "late". Both factors will push the single sex ratio down, towards a surplus of women.

\subsection{Restrictions on $P$ And $Q$ and a Word on Market Congestion}

The random component to the search process, described by the meeting probability functions $P$ and $Q$, can be seen as a black box capturing any restrictions on age targeting, from actual "physical" restrictions to social norms surrounding marriage. To give some examples, practically all marriages in India in the time period of interest were initiated and negotiated by family members, and young girls were kept in the house after puberty, so that age is not fully observable. Matchmakers or parents may also first propose the oldest son or daughter to an approaching family before discussing other possible matches. More generally, conventions may require a family to go through the motions and give each potential match full consideration even if there is no real interest, slowing the search process down. ${ }^{12}$

\footnotetext{
${ }^{12}$ Caldwell et al. (1983) report for instance that "[t]raditionally, marriages to relatives have been preferred, and to a very considerable extent the parents (...) could insist on such
} 
So far I have made no assumptions on the actual shape of the meeting probabilities. Since there is a continuum of people at each age, the probability of meeting must be equal to the proportions of men and women who meet. Each man or woman can meet only one person at a time, so the mass of women of age $i$ who meet age- $j$ men, $P_{i j} W_{i t}$, must equal $Q_{j i} M_{j t}$, the mass of age- $j$ men meeting age- $i$ women. At the same time, using the relations between absolute and relative population numbers, $P_{i j} W_{i t}=P_{i j} \frac{w_{i}}{r m_{j}} M_{j t}$, so that $Q_{j i}=P_{i j} \frac{w_{i}}{r m_{j}}$.

Beyond this condition, we may want to impose further restrictions on the effect of $d$ onto $P$ and $Q$. As a first simplification I assume that $P$ and $Q$ are separable in $r$ and $(w, m)$. Then $P_{i j}$ can be rewritten as the product $\lambda_{w}(r) \cdot p_{i j}(w, m)$ with $\sum_{j=1}^{J} p_{i j}=1$. The function $\lambda_{w}$ sets the "speed" of the marriage market for women - the average rate at which they meet men - whereas $p_{i j}$ describes the probability that the man is of a certain age. Equivalently, $Q_{j i}$ can be decomposed as $\lambda_{m} q_{j i}$. Summing up over $i$ and $j$, the $\lambda$ 's must satisfy $\lambda_{w}(r) W_{t}=\sum_{i=1}^{I} \sum_{j=1}^{J} \lambda_{w} p_{i j} W_{i t}=\sum_{i=1}^{I} \sum_{j=1}^{J} Q_{j i} M_{j t}=\lambda_{m}(r) M_{t}$, or $\lambda_{w}(r)=r \lambda_{m}(r)$, so that $q_{j i}=\frac{w_{i}}{m_{j}} p_{i j}$. The response of the $\lambda$-functions to $r$ reflects the "congestion" in the market due to an unbalanced sex ratio. Plausibly $\lambda_{w}$ is increasing in $r$ and $\lambda_{m}$ is decreasing, so that the overall meeting probability for women rises with the relative number of men and vice versa. The $\lambda$ must be bounded by $[0,1]$. "Symmetric" congestion would arise, for example, if $\lambda_{w}=\lambda_{m}^{-1}=\sqrt{r}$ (within these bounds).

In addition I will assume that $p_{i j}$ and $q_{j i}$ are independent of $w$ and $m$, respectively, so that there are no "relative competition" effects between age groups on the same side of the market (e.g. a larger proportion of young women does not reduce the meeting rates of an

a marriage taking place", but that there was increasing "temptation for the boy's parents to seek a marriage outside the family". In addition, age is but one of many important characteristics to consider in a marriage. The families' caste, status and wealth, previous relations between them, the partners' health and education, and, last but not least, astrology all play a role. One can think of a variation of the model with an idiosyncratic error term to the match surplus, which is realized only upon meeting. If this error has a large enough variance, no age will be a priori excluded from consideration. The main conclusions of the model remain the same. 
older woman if $r$ is the same). Note that this implies $p_{i j}=m_{j}$ and $q_{j i}=w_{i}$. This assumption is attractive both for its convenience and because it implies that the age of the man (woman) an individual meets is a simple random draw from the male (female) age distribution.

The specific assumptions of separability and pure random sampling are not necessary for many of the results that follow, but they will be used in the estimation in section 5 and warrant a brief discussion of the restrictions they impose. Under separability the effect of $r$ on the meeting rates $\lambda$ can be interpreted as the "pure" congestion effect in the model. The "composition" effect is seen best when letting $\lambda_{w}(r)=\min \{1, r\}$ and $\lambda_{m}(r)=\min \{1,1 / r\}$, so that the short side of the market has a meeting probability of one, and the meeting rate decreases one-to-one in the singles sex ratio for the other side. Suppose $r>1$, so that the women's meeting rates are constant $\left(\lambda_{w}=1\right)$, and consider the change in meeting probabilities when the male population above the median age $j_{\text {med }}$ doubles. The "pure" congestion effect implies that each man will be less likely to meet a woman of any age group in a given time period. But while women's overall meeting rates stay the same, the "composition" effect means that the probability of meeting a man younger than $j_{\text {med }}$ will shrink from one half to one third, even though there are the same numbers of young men and of women in the market as before. In other words, the older men crowd out some of the encounters between young men and women. This effect is at play whenever the meeting rate changes by less than $r$ (or $\frac{1}{r}$ ), and this must be the case for at least one side of the market.

The composition effect may seem somewhat counterintuitive at first. But suppose the crowding out effect of old on young men in the example above can be reduced by choosing different $P$ and $Q$. Doing so is implicitly based on the assumption that women would prefer to meet younger men. However, while the payoffs to marriage $\pi$ are fixed, actual preferences over marriage ages are endogenous to the model; for instance, even vastly different ages may want to marry if "the price is right". More generally, letting meeting probabilities depend on age preferences would in effect allow individuals to target their search towards partners of a 
specific (preferred) age, thereby indirectly reducing search frictions. ${ }^{13}$ Yet the main argument of this paper is that the search process in this market is not free of frictions and that there are some barriers to age targeting. Moreover, the frictionless model has implications for the effect of a marriage squeeze that contradict the data from India. Thus, while the precise distributional assumptions for $P$ and $Q$ might be debated, search frictions and the associated congestion effects seem a good approximation of the realities of the marriage market.

\subsection{The Value Functions}

Let us turn to marriage decisions. In the derivation of the steady-state singles distribution, we took the marriage indicator matrix $A$ as given, but in equilibrium it is of course the result of the market participants' individual choices. Upon meeting, men and women compare the payoff to marrying with the outside value of being single and remaining in the market. This section derives the value functions that describe the individuals' outside options and determine their choice to marry. It focuses again on the women's side of the market, stating the equivalent expressions for the mens' side without derivations.

Omitting time indices, summarize by $\pi_{b}(i, j)$ and $\pi_{g}(i, j)$ the (expected) discounted future payoffs of marriage for a bride and a groom at age $i$ and $j$, respectively, and let $D_{i j}$ be the dowry paid by the bride's to the groom's family. A couple will marry upon meeting if they both prefer marrying each other over continuing search. The woman agrees to marry if the net payoff $\pi_{b}(i, j)-D_{i j}$ exceeds the expected value of remaining single, $\delta\left(s_{i+1} B_{i+1}+\left(1-s_{i+1}\right) H\right)$, where $\delta$ is the discount factor, $B_{i+1}$ is the value of search at $i+1$, and $H$ is the payoff when not surviving to the next age. $H=0$ on the assumption that death is independent of the marriage decision and men and women compare the additional value of marriage to the outside option of being single (so that all payoffs are understood as relative payoffs from marriage). Equivalently, the man compares his outside option $\delta z_{j+1} G_{j+1}$ with $\pi_{g}(i, j)+D_{i j}$.

\footnotetext{
${ }^{13}$ Note also that targeted search by age implies that any variation in partners' marriage age is a choice. Every individual at a certain age must then marry exactly one age group, or be indifferent between all ages married, unless there is additional taste variation.
} 
The expected dowry payment is assumed to be the outcome of a generalized Nash bargaining problem, given by

$$
D_{i j}=\arg \max _{D}\left[\pi_{b}(i, j)-D-\delta s_{i+1} B_{i+1}\right]^{\theta}\left[\pi_{g}(i, j)+D-\delta z_{j+1} G_{j+1}\right]^{(1-\theta)}
$$

where $\theta$ describes the woman's bargaining power. This means that the dowry is

$$
D_{i j}=(1-\theta)\left(\pi_{b}(i, j)-\delta s_{i+1} B_{i+1}\right)-\theta\left(\pi_{g}(i, j)-\delta z_{j+1} G_{j+1}\right),
$$

and the net payoff to the woman from marrying is therefore

$$
\delta s_{i+1} B_{i+1}+\theta\left(\pi_{b}(i, j)-\delta s_{i+1} B_{i+1}+\pi_{g}(i, j)-\delta z_{j+1} G_{j+1}\right) .
$$

She receives her outside option, plus a share $\theta$ of the net marriage surplus. As long as this share is positive, she will agree to marry. Similarly, the groom receives his outside option plus a $(1-\theta)$ share of the net surplus, and will want to marry whenever the net surplus is positive. This implies that the marriage decisions of a couple $(i, j)$ coincide and can be described by a single function $\alpha$ indicating a positive net surplus.

Another way of saying this is that I assume that a couple will marry whenever their net surplus of marriage is nonnegative. The transfers at marriage have to be such that both partners prefer marrying to their outside option. If the marriage surplus is strictly positive, a set of prices - any $\theta$ between 0 and 1 - satisfy this condition. The choice of an exogenous, fixed $\theta$ serves to pin the transfer payment down. ${ }^{14}$ The endogenous element of the partners' relative bargaining power is given by the value functions, which reflect market conditions.

The expected value of search $B_{i}$ for a woman at age $i$ is given by the maximized expected value of meeting with men of ages $j=1, \ldots, J$ according to the singles distribution and the meeting probability functions. For the value function (although not the dowry) it is not important who receives which share of the marriage surplus, so we can summarize $\pi_{b}(i, j)+$ $\pi_{g}(i, j)=\pi(i, j)$. Letting $S(i, j)=\pi(i, j)-\delta s_{i+1} B_{i+1}-\delta z_{j+1} G_{j+1}$, this can be written

\footnotetext{
${ }^{14} \mathrm{~A}$ strictly positive surplus in a market with many identical agents is possible because search frictions prevent direct competition, as in the classical job search model.
} 
recursively as

$$
B_{i}=\delta s_{i+1} B_{i+1}+\sum_{j=1}^{J} P_{i j} \theta \max \{0, S(i, j)\},
$$

where $S(i, j)=\left[\pi(i, j)-\delta s_{i+1} B_{i+1}-\delta z_{j+1} G_{j+1}\right]$ is the net surplus at marriage for $i$ and $j$. Equivalently,

$$
G_{j}=\delta z_{j+1} G_{j+1}+\sum_{i=1}^{I} Q_{j i}(1-\theta) \max \{0, S(i, j)\},
$$

Let the outside options at the final age of market participation be $B_{I+1}=G_{J+1}=0$, respectively. The individually maximizing marriage strategy for couple $(i, j)$ that is embedded in the value functions is described by the marriage market indicator $\alpha_{i j}$. Finally, observe that the value of search for the bride is bounded by 0 and $\bar{B}=\frac{1-\delta^{I}}{1-\delta} \theta \max _{(i, j)} \pi(i, j$ ) (with the equivalent expressions for $G$ ).

Note that the age of entering or leaving the market and the lowest and highest age at which an individual may get married need in principle not coincide in equilibrium: the age distribution may capture people who "clutter" the market and attempt to meet a partner, without ultimately marrying anyone. This implies that the value function may be increasing in age over some range.

Now we are in a position to define the marriage market equilibrium.

Definition 2.1 (Marriage Market Equilibrium). For a given payoff function $\pi$ and parameters $\delta, s, z, b, s_{0}$ and $a$, an equilibrium consists of an indicator matrix $A$, value functions $B$ and $G$, and singles distributions $m$ and $w$ such that

a)For all $(i, j), \alpha_{i j}=0$ if $S(i, j)<0, \alpha_{i j}=1$ if $S(i, j)>0$, and $\alpha \in[0,1]$ if $S(i, j)=0$.

b) $m$ and $w$ are steady-state distributions for $\alpha$ satisfying equations (2.1)-(2.4), and

c) $B_{i}$ and $G_{j}$ are the value functions arising from $m$ and $w$ according to (2.6)-(2.7), with end point conditions $B_{I+1}=\underline{B}$ and $G_{J+1}=\underline{G}$.

In a steady-state equilibrium, individuals' decisions based on $m$ and $w$ coincide with the marriage indicator matrix that produces those same steady-state singles distributions. Men and women's expectations about meeting probabilities later in life are correct and identical to current market conditions. 
Confirming existence of a matching equilibrium is an application of Kakutani's fixed point theorem. We can define a map from the set of possible $d$ and $A$ into itself. The new singles distribution is given by equations (2.1)-(2.4). The new $A$ is derived from a set of new value functions for $d$; since the singles distribution determines the meeting probabilities $P$ and $Q$, it can be shown that the mapping given by equations (2.6) and (2.7) is a contraction, and therefore has the two value functions $B$ and $G$ as its unique fixed point.

Lemma 2.2 (Value Function). Suppose $m$ and $w$ are given and the effective discount factors $\delta s_{i}$ and $\delta z_{j}$ are less than one for all $i$ and $j$. Then the corresponding value functions $B$ and $G$ exist and are unique.

It is then straightforward to verify that this map satisfies the conditions for Kakutani's theorem and that its fixed point is a marriage market equilibrium.

Theorem 2.3 (Existence of Equilibrium). If the effective discount factors are less than one there exists a matching market equilibrium.

Note, however, that the equilibrium as a whole need not be unique. I will return to this issue in section 4 .

\section{ExAmples}

The following examples show that the model can simultaneously explain the observed changes in marriage age patterns and dowry inflation as the result of demographic change.

Demographics affect average marriage ages through the age distribution, the meeting rates, and marriage choices. For example, suppose the singles sex ratio falls. Holding the age distributions and marriage decisions fixed, women's arrival rates of potential matching partners decrease at every age, leading to marriage delay and an "older" age distribution for women. But changes in one age distribution generally affect that on the other market side, and ultimately outside options and marriage decisions, so that the matching sets will change, leading to further shifts. For instance, men's matching sets "shifting up" to exclude younger women and/or include older ones is equivalent to marriage postponement by women, and all else equal this will again lead to higher average marriage age. 
The argument for dowries is similar: changes to the relative numbers of observed matches will affect average dowries. However, it is not a priori clear which age combinations produce high dowries and which produce low ones. In addition, changing outside options will also alter the amount of dowry that is paid in any given match, because the dowry depends on the partners' value of search (the conditional dowry change, see section 4). The sum of all these effects is quite complex. This section provides examples in which an increase in population growth $g$ leads to higher average dowries while also shrinking the marriage age gap. Throughout we will assume that $\lambda_{w}=\lambda \min \{1, r\}$ and $\lambda_{m}=\lambda \min \left\{1, \frac{1}{r}\right\}$ with $\lambda<1$.

\subsection{Example 1: 2x2 Symmetric Case}

Consider an example with just two age levels. For a small number of ages, the discrete model is tractable enough to find all pure-strategy equilibria by trial and error (by guessing a set of $\alpha$ 's, solving for the age distributions and value functions, and checking if the $\alpha$ correspond to men's and women's optimal behavior). Note that a $(2,2)$ couple will marry whenever $\pi(2,2)>0$, and we will restrict attention to profit functions with this property. The bride and groom contribute equally to the marriage payoff, i.e. $\pi_{b}(i, j)=\pi_{g}(i, j)=$ $\frac{1}{2} \pi(i, j)$, and the Nash bargaining parameter $\theta$ equals 0.5 . Finally, assume that the age gap at market entry is zero, and the birth sex ratio and survival rates equal one.

The value of being single at age 2 is, for the bride and groom

$$
\begin{aligned}
& B_{2}=0.5 \alpha_{21} \lambda_{w} m_{1}\left(\pi(2,1)-\delta G_{2}\right)+0.5 \lambda_{w}\left(1-m_{1}\right) \pi(2,2) \\
& G_{2}=0.5 \alpha_{12} \lambda_{m} w_{1}\left(\pi(1,2)-\delta B_{2}\right)+0.5 \lambda_{m}\left(1-w_{1}\right) \pi(2,2) .
\end{aligned}
$$

Optimal strategies imply that $\alpha_{11}=1$ whenever $\delta\left(B_{2}+G_{2}\right)<\pi(1,1)$ and 0 otherwise. Similarly, $\alpha_{12}$ is one if $\delta B_{2}<\pi(1,2)$, and $\alpha_{21}$ equals 1 whenever $\delta G_{2}<\pi(2,1)$.

This version of the model is completely symmetric apart from the payoff function at $(1,2)$ and $(2,1)$. This means that $w_{1}=m_{1}$ and $r=1$ when $\alpha_{12}=\alpha_{21}$. Suppose the payoff function is such that both $\alpha_{12}$ and $\alpha_{21}$ equal one. In this case, the value functions are identical for both the bride and the groom, except for the difference in the marriage payoffs for couples with different ages. The two value function equations constitute a linear system, and it is straightforward to show that $B_{2}<G_{2}$ whenever $\pi(2,1)<\pi(1,2)$. In other words, if 
the marriage of a young woman with an old man is preferred over the opposite pairing, a woman's outside option at age 1 will generally be lower than that of a man. What is more, the difference $G_{2}-B_{2}$ is increasing in $m_{1}$, meaning that if there are relatively more young men (and therefore more young women, since $w_{1}=m_{1}$ ) in the market, the women's relative bargaining position worsens. The dowry for $(1,1)$ couples must rise, and with it the average dowry $D$, since

$$
D=0.5 m_{1}^{2} \delta\left(G_{2}-B_{2}\right)+0.5 m_{1}\left(1-m_{1}\right) \delta G_{2}-0.5 m_{1}\left(1-m_{1}\right) \delta B_{2}=0.5 m_{1} \delta\left(G_{2}-B_{2}\right) .
$$

Finally, it can be shown that $m_{1}$ is strictly increasing in $g$; as the growth rate increases, younger cohorts become relatively larger, and the average dowry goes up. ${ }^{15}$

In this example, both the effect of demographic change on the value functions and on the probability weights work to increase the average dowry. Moreover, dowry inflation occurs even though strategies do not change at all. However, the increased number of young people in the market means that the average marriage age for both men and women falls here as $g$ rises, and due to symmetry the average age gap at marriage is always zero. In Example 2 the predictions of the marriage squeeze hypothesis are fully borne out.

\subsection{Example 2: Strategic marriage postponement}

In this example, I show that the age gap change predicted by the marriage squeeze can obtain when women "postpone" as $g$ increases. Starting from an equilibrium in which the couple $(2,1)$ does not match, the marriage surplus between $(2,1)$ turns positive as $g$ increases, and they begin to marry. The second, symmetric equilibrium is exactly that of Example 1.

Let $\lambda=0.5$, and let the payoff function be given by $\pi(1,1)=7, \pi(1,2)=4.2, \pi(2,2)=35$, $\pi(2,1)=2.7$. Suppose that $g$ lies between -0.15 to 0.4 ; the marriage surplus for all couples

\footnotetext{
${ }^{15}$ Note that $\left(1-m_{1}\right)=\frac{\psi_{1}}{1+g} m_{1}$ (equation 2.2), where $\psi_{1}=1-\lambda\left(\alpha_{11} w_{1}+\alpha_{12}\left(1-w_{1}\right)\right)$. Using that $m_{1}=w_{1}$ and $\alpha_{12}=1$, we can solve directly for $m_{1}$ for all possible $\alpha_{11}$. The simplest case is $\alpha_{11}=1$ : then $\psi_{1}=1-\lambda$, and $m_{1}=\frac{1+g}{2+g-\lambda}$. This last equation illustrates that $\lambda<1$ is needed for strict monotonicity of $m_{1}$ in $g$. If all $(1,1)$ couples meet and marry $\left(\lambda=1, \alpha_{11}=1\right)$, no one will ever reach age 2 , so that the outside options are independent of $g$.
} 

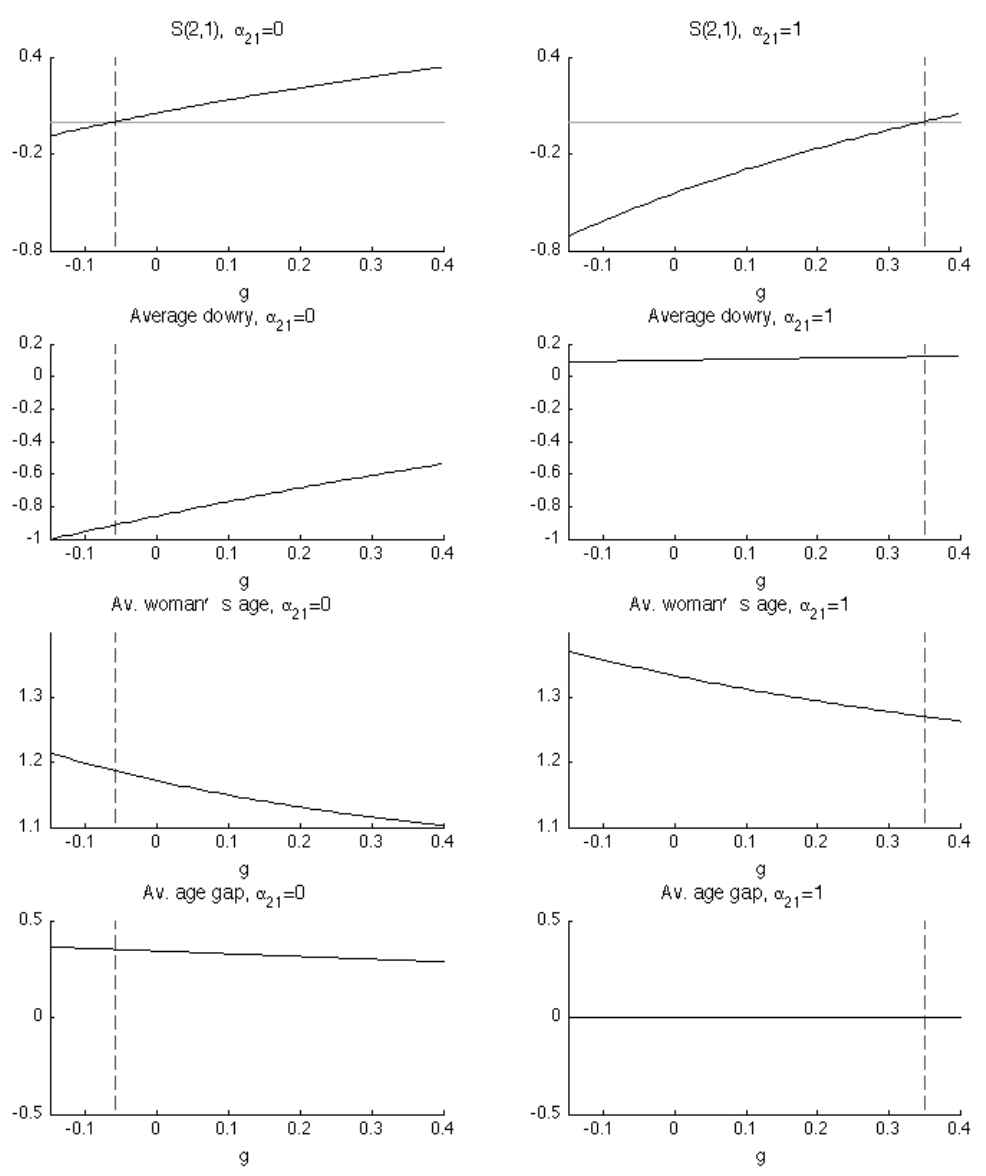

Figure 2. An example with $\lambda=0.5, \pi(1,1)=7, \pi(1,2)=4.2, \pi(2,2)=35$, $\pi(2,1)=2.7 . \alpha_{21}=0$ left and $\alpha_{21}=1$ right.

except $(2,1)$ is then positive for every value of $g$. Omitting the algebra, figure 2 illustrates the behavior of $S(2,1)=\pi(2,1)-G_{2}$ as $g$ increases for both $\alpha_{21}=0$ and $\alpha_{21}=1$ (top panel), and the corresponding changes in average dowry, women's age, and the age gap at marriage. The marriage surplus of couple $(2,1)$ is increasing in both cases, so that $\alpha_{21}=0$ can be an equilibrium only as long as $g<-0.06$. For $\alpha_{21}=1, g>0.35$ leads to a pure strategy equilibrium (so that $S(2,1)>0$ ). The demographically driven switch between the two equilibria leads simultaneously to an increase in dowries from a negative to a positive average payment (i.e. a switch "from brideprice to dowry"), a rise in the women's average marriage age, and a fall in the marriage age gap from more than 0.3 to 0 . 
TABLE 2. Example 3

\begin{tabular}{|c|c|c|c|c|c|c|}
\hline $\mathrm{g}$ & -0.01 & 0 & 0.01 & 0.02 & $\ldots$ & 0.05 \\
\hline Dowry & -6.63 & -6.52 & 0.29 & 6.33 & $\ldots$ & 6.85 \\
\hline Women's marriage age & 1.05 & 1.00 & 1.00 & 1.31 & $\ldots$ & 1.48 \\
\hline Men's marriage age & 5.40 & 5.35 & 5.00 & 5.00 & $\ldots$ & 5.07 \\
\hline Age gap & 4.35 & 4.34 & 4.00 & 3.69 & $\ldots$ & 3.59 \\
\hline
\end{tabular}

\subsection{Example 3: Value Functions and Probability Weights Trump Strategies}

This 5-by-5 example shows that the effect of the growth rate on the equilibrium outcome need not be driven by changing strategies. When there are more ages, the model can be solved numerically to search for pure strategy equilibria. Assume that there are five age groups, and that the age gap at market entry $a$ equals four. The payoff function is given by $20-(2-i)^{2}-(2-j)^{2}$ (i.e. an inverted quadratic with a maximum at $(2,2)$ ). Following typical demographic patterns, the birth sex ratio $b$ was set to 1.04 , survival rates are close to one, and $\lambda=0.99$. Table 3.3 shows the evolution of the average dowry and marriage ages for men and women for a series of population growth rates: From $g=0.01$ on, dowry and relative marriage ages change in the directions expected by the dowry inflation/marriage squeeze hypothesis. However, marriage decisions reveal marriage preponement by women and marriage delay by men. The last row in the table shows the age combinations (with $i$ on the x-axis) who marry in equilibrium shaded in grey. Most $\alpha$ equal one, but at the outset where $g=-0.01, \alpha_{15}, \alpha_{25}$ and $\alpha_{14}$ are zero, that is, young women do not marry very old men; as $g$ increases, those zeros disappear, and at $g=0.01$ all couples marry. At $g=0.05$, $\alpha_{51}, \alpha_{52}$, and $\alpha_{41}$ are zero. In other words, the matching sets of men exclude old women as $g$ grows, and include more young women. Nevertheless, the probability weights effect cancels this out, and the average marriage age of women increases gradually. At the same time, even though dowries at any $g$ are highest between old women and young men (who cease to marry as $g$ progresses), and lowest (negative) between young women and old men (who 
begin to marry), the conditional dowries for all $(i, j)$ combinations increase enough to raise the average dowry. Note that the annual growth rate changed roughly from 0.01 to 0.02 between 1911 and 1971.

\section{Dowry Conditional on Marriage Ages}

As seen in the previous section, the effect on the equilibrium of a change in population growth is quite complex, due to the various and possibly opposing effects at play. Even if strategies do not change at all, the market moves into a new demographic steady-state given by equations (2.1)-(2.4). Moreover, uniqueness of the matching equilibrium is not guaranteed. But this problem can be sidestepped by directly comparing two equilibria by their singles distributions $(w, m, r)$. It will be shown that a market equilibrium with a lower sex ratio $r$ must have lower dowry payments between all matched couples. A similar statement can be made for certain changes in $w$ or $m$ if the matching patterns in at least one equilibrium are known.

This exercise does not deliver full comparative statics for an increase in $g$, and not all equilibria are comparable in this way. But the approach has the advantage that the equilibrium value functions are unique given the singles distribution, so that unambiguous comparisons are possible. Using demographic data from Karnataka it will be shown that the changes to the singles distribution during the squeeze strongly suggest an increase in dowries. ${ }^{16}$

Recall that the dowry between $i$ and $j$ is given by

$$
D_{i j}=(1-\theta) \pi_{b}(i, j)-\theta \pi_{g}(i, j)+\theta \delta z_{j+1} G_{j+1}-(1-\theta) \delta s_{i+1} B_{i+1}
$$

Suppose $g$ changes and the market moves to a new equilibrium with a new $d=(m, w, r)$. For constant marriage payoffs and a given set of model parameters $(\delta, \lambda, \theta)$, the change in the transfer between $i$ and $j$ depends entirely on the effect on the value functions. Thus,

${ }^{16}$ Note also that the Indian census only provides age distributions (i.e. $r, w$, and $m$ ). Vital registration (i.e. the collection of birth and mortality data) was only introduced with the Sample Registration System in 1969-70, so that $g, b, m$ and $z$ are actually not directly observed. 
showing that $G$ must increase and/or $B$ decrease is enough to prove that the dowry between $i$ and $j$ must rise (and the reverse).

Define the map $\boldsymbol{B}_{d}:[0, \bar{G}]^{J} \rightarrow[0, \bar{B}]^{I}$ such that for given $d, \boldsymbol{B}_{d}(G)$ is the women's value function for fixed $G$ (equation (2.6)). Equivalently, let $\boldsymbol{G}_{d}:[0, \bar{B}] \rightarrow[0, \bar{G}]^{J}$ be the solution to equation (2.7) for given $B$. Note that in an equilibrium with $d^{*}$ as the equilibrium singles distribution and value functions $\left(B^{*}, G^{*}\right)$, it must be that $\boldsymbol{B}_{d^{*}}\left(G^{*}\right)=B^{*}$ and $\boldsymbol{G}_{d^{*}}\left(B^{*}\right)=G^{*}$. Furthermore, for given $d^{*}, B^{*}$ and $G^{*}$ exist and are unique, as was assured by lemma 2.2.

Now suppose we know that for a second singles distribution $d^{* *}, \boldsymbol{B}_{d^{* *}}\left(G^{*}\right) \leq \boldsymbol{B}_{d^{*}}\left(G^{*}\right)$ and $\boldsymbol{G}_{d^{* *}}\left(B^{*}\right) \geq \boldsymbol{G}_{d^{*}}\left(B^{*}\right)$. This is enough to guarantee that the equilibrium value functions $B^{* *}$ and $G^{* *}$ associated with $d^{* *}$ satisfy $B^{* *} \leq B^{*}$ and $G^{* *} \geq G^{*}$. To show this, we use

Lemma 4.1. Given $d, \boldsymbol{B}_{d}$ is decreasing in $G$, and $\boldsymbol{G}_{d}$ is decreasing in $B$.

Proof Let $\hat{G} \geq G$. We want to show that $\boldsymbol{B}(\hat{G})_{i} \leq \boldsymbol{B}(G)_{i}$ for all $i$ (suppressing the $d$ subscript). ${ }^{17}$ Thus, by contradiction suppose $i$ is the highest age at which $\boldsymbol{B}(\hat{G})_{i}>\boldsymbol{B}(G)_{i}$. Let $\hat{\alpha}_{i j}$ be the optimal marriage decisions for $\hat{G}$ and $\boldsymbol{B}(\hat{G})$. But then

$$
\begin{aligned}
\boldsymbol{B}(\hat{G})_{i} & =\left(1-\sum_{j=1}^{J} P_{i j} \theta \hat{\alpha}_{i j}\right) \delta s_{i+1} \boldsymbol{B}(\hat{G})_{i+1}+\sum_{j=1}^{J} P_{i j} \theta \hat{\alpha}_{i j}\left[\pi(i, j)-\delta z_{j+1} \hat{G}_{j+1}\right] \\
& \leq\left(1-\sum_{j=1}^{J} P_{i}(j, d) \theta \hat{\alpha}_{i j}\right) \delta s_{i+1} \boldsymbol{B}(G)_{i+1}+\sum_{j=1}^{J} P_{i}(j, d) \theta \hat{\alpha}_{i j}\left[\pi(i, j)-\delta z_{j+1} G_{j+1}\right] \\
& =\delta s_{i+1} \boldsymbol{B}(G)_{i+1}+\sum_{j=1}^{J} P_{i}(j, d) \theta \hat{\alpha}_{i j}\left[\pi(i, j)-\delta s_{i+1} \boldsymbol{B}(G)_{i+1}-\delta z_{j+1} G_{j+1}\right] \\
& \leq \boldsymbol{B}(G)_{i} .
\end{aligned}
$$

The first inequality comes from the assumption on $G$ and $\hat{G}$ and the fact that we are looking at the last age at which $\boldsymbol{B}(\hat{G})_{i}>\boldsymbol{B}(G)_{i}$. The second inequality uses that $\hat{\alpha}$ is not optimal for $G$ and $\boldsymbol{B}(G)$. Thus, we established the contradiction. The proof for $\boldsymbol{G}$ is identical.

This lemma allows the construction of two sequences $G_{n}$ and $B_{n}$ as follows:

\footnotetext{
${ }^{17}$ There is at least one $\hat{i}$ for which this holds since $B_{I+1}=0$.
} 


$$
\begin{array}{rlrl}
G_{1} & =\boldsymbol{G}_{d^{* *}}\left(B^{*}\right) \stackrel{(a)}{\geq} \boldsymbol{G}_{d^{*}}\left(B^{*}\right)=G^{*} & B_{1} & =\boldsymbol{B}_{d^{* *}}\left(G_{1}\right) \leq \boldsymbol{B}_{d^{* *}}\left(G^{*}\right) \stackrel{(b)}{\leq} \boldsymbol{B}_{d^{*}}\left(G^{*}\right)=B^{*} \\
G_{2}=\boldsymbol{G}_{d^{* *}}\left(B_{1}\right) & B_{2}=\boldsymbol{B}_{d^{* *}}\left(G_{2}\right) \\
& \ldots & \cdots & \\
G_{n}=\boldsymbol{G}_{d^{* *}}\left(B_{n-1}\right) & B_{n}=\boldsymbol{B}_{d^{* *}}\left(G_{n}\right)
\end{array}
$$

Provided (a) and (b) are true (by assumption), $B_{n}$ is decreasing and $G_{n}$ increasing, and since both sequences are bounded, they converge to limit value functions $B$ and $G$. It can be shown that these limits are equilibrium value functions for the new $d^{* *}$ (see appendix), and by lemma 2.2 , they are the unique value functions. This implies $B=B^{* *} \leq B^{*}$ and $G=G^{* *} \geq G^{*}$.

Now all we need are conditions on $d^{*}$ and $d^{* *}$ that actually make (a) and (b) hold.

\section{Theorem 4.2. Suppose}

(1) the singles sex ratio is higher in $d^{*}$ than in $d^{* *}$, and/or

(2) the women's age distribution in $d^{*}$ shifts weight from ages $i$ with higher $\pi(i, j)-$ $\delta s_{i+1} B_{i+1}^{* *}$ to those with lower $\pi(i, j)-\delta s_{i+1} B_{i+1}^{* *}$, compared to $d^{* *}$.

Then the equilibrium value functions $B^{* *}$ and $G^{* *}$ for $d^{* *}$ are such that $B^{* *} \leq B^{*}$ and $G^{* *} \geq G^{*}$ (with at least one strictly different if $r^{*}>r^{* *}$ in (1)), and dowry payments will be higher under $d^{* *}$ for all couples who marry in both equilibria. An equivalent statement to (2) holds for the men's side of the market.

The proof for each of these claims works in a similar manner as the proof for lemma 4.1 and is in the appendix. Part (1) of the theorem means that the intuition about a "shortage" of men holds; if the number of single men relative to single women falls, the dowry will increase, because the outside value of search deteriorates for women but improves for men. Part (2) builds on a similar argument: for a man at a given age $j$, a high $\pi(i, j)-\delta s_{i+1} B_{i+1}$ is synonymous with a high net marriage surplus. If there are two equilibria with women's age distributions $w^{*}$ and $w^{* *}$, and $w^{*}$ "shifts" probability mass from high-surplus ages to low-surplus ones compared to $w^{* *}$, the value of search for men will be lower, and conditional 
dowries therefore smaller, under $w^{*}$. This result is particular useful if we know the matching set (that is, $A$ ) in at least one of the equilibria, because we know for sure that $\pi(i, j)-$ $\delta s_{i+1} B_{i+1}$ must be lower outside $j$ 's matching set than inside. In particular, the search value for men must fall if $d^{*}$ shifts probability weight from the men's matching set under $d^{* *}$ towards a set of ages $i$ outside it. Formally, this becomes

Corollary 4.3. Let $\mathbb{I}$ be the union of all matching sets $\mathbb{I}(j)$ under $w^{* *}$, and suppose $w^{*}(i) \leq$ $w^{* *}(i)$ for all $i \in \mathbb{I}$. Then the equilibrium value functions for $d^{*}$ and $d^{* *}$ are such that $B^{*} \geq B^{* *}$ and $G^{*} \leq G^{* *}$.

\subsection{Data and Implications for Conditional Dowries}

Now I can use data from the Indian state Karnataka at the beginning and end of the marriage squeeze to apply these results. As will be seen, theorem 4.2 and corollary 4.3 describe very closely how the singles distributions changed in Karnataka, with $d^{*}$ the singles distribution before the marriage squeeze and $d^{* *}$ afterwards: the singles sex ratio fell, and at the same time, the age distribution of women after the squeeze puts more probability weight on those age groups who marry, and therefore must have a high net marriage surplus.

Karnataka (Mysore) was chosen for several reasons. It is a large state in the South, where marriages tend to be isogamous (between caste equals), so that any groom shortage is likely demographic rather than due to the scarcity of high caste men (Caldwell et al. (1983), Billig (1991)). Moreover, marriage age has been comparatively high for both sexes (Agarwala (1957)) and legislation against child marriage was in place as early as 1894 (Marten (1923)). These circumstances make it less likely that the change in marriage age was caused by shifting age preferences e.g. due to higher rates of schooling. Finally, Mysore's location and population composition (92\% Hindu in 1931) imply that it was less affected by migration flows after the partition of India in 1947 than other large states. ${ }^{18}$

\footnotetext{
${ }^{18}$ Like most states Mysore's borders were reorganized in 1956, but unlike many of them it was not divided. Mysore was enlarged to include Coorg (Kodagu) and several neighboring districts from Bombay, Hyderabad, and Madras (and renamed Karnataka in 1973). Since the reorganization took place to align state boundaries with linguistic boundaries, I assume
} 
The analysis in this section and in the estimation of the next section must rely on two assumptions. First, the marriage market before and after the squeeze must be in a steady state. ${ }^{19}$ Figure 1 shows two plateaus in Karnataka's growth rate, between 1921 and 1941 and between 1961 and 1981. I will consider the census of 1971, supplemented by NFHS data from all marriages between 19m63 and 1979, the "endpoint" of the marriage squeeze. The choice of starting point is a little more problematic, since the 1941 census was not carried out in full due to World War II, and 1901 and 1921 were preceded by famines and epidemics. But the marriage age records in the census of 1931 may be distorted by the enactment of the Child Marriage Restraint Act in April 1930, which outlawed a girl's marriage under 14 and a boy's under 18. Although there were no longterm effects, many parents seem to have rushed to marry their children in 1929 and early 1930, leading to a one-time decrease in marriage ages in many states in 1931 (see table 1). I will therefore use both the census data from 1911 and from 1931 as approximations of the steady-state age distribution before the marriage squeeze.

The second assumption is that marriage age preferences $\pi$ are unchanged over the period of the marriage squeeze. This is supported by the relative stagnation in economic growth described earlier. Moreover, the total fertility rate was high throughout and did not appreciably fall until after 1971 (5.75-5.86 in 1911-31, and 5.78 in 1966-71 Bhat (1989); Rele $(1987)))$, indicating that preferences over fertility timing and therefore marriage age did likely not change substantially either. Finally, educational attainment - as a potential shifter for marriage age preferences - was still low in 1971, with a female literacy rate below $19 \%$ (IndiaStat (2009)). ${ }^{20}$ Nonetheless, if families in 1971 preferred a higher marriage age for women that Mysore's demographics are representative for the geographic area of today's Karnataka. The marriage age estimates for both geographic areas in table 1 are quite similar.

${ }^{19} \mathrm{Or}$ well-described by a steady-state equilibrium, e.g. because individuals have adaptive expectations.

${ }^{20}$ Evidence from Bangladesh even suggests that the correlation between marriage age and schooling is the result of parents taking their daughters out of school as soon as they reach menarche, so that the preferred marriage age determines length of schooling rather than the other way around (Ambrus and Field (2008)). 
FiguRE 3. NFHS marriage ages, marriages in 1963-1979 (grey: 45 degrees)

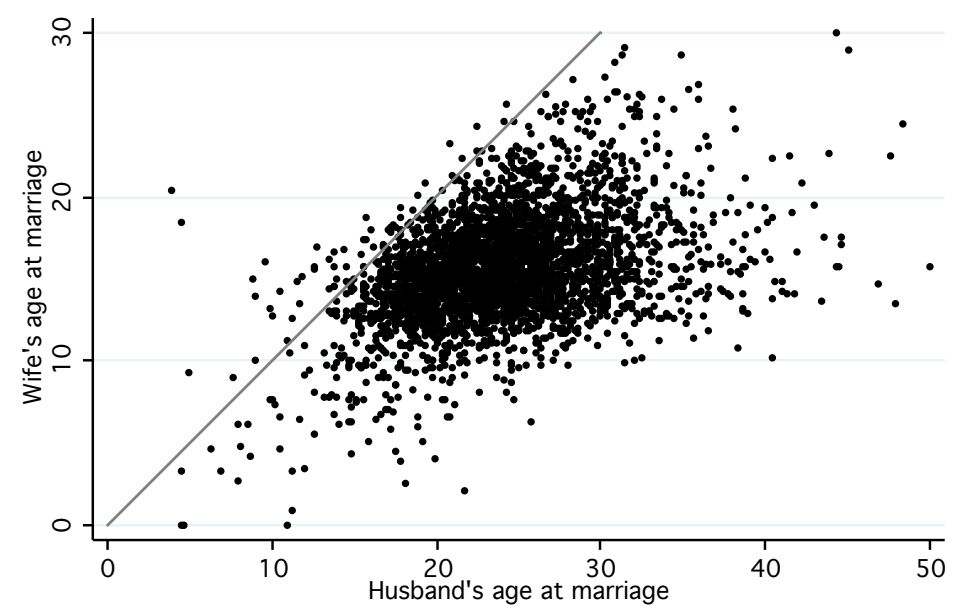

than in 1931 or 1911, the assumption of constant age preferences may somewhat overstate the pressure on the women's market side from marriage delays caused by the squeeze.

The data that used here and in the next section consists of the census counts from 1911, 1931, and 1971 of the numbers of never married and all men and women by age group (Padmanabha (1973), Gait (1913), Hutton (1933)), and of survey data from the National Family Health Survey (NFHS). The census provides the singles distributions. For the 1971 singles distribution, the adjusted total age returns of the census were combined with the data for marital status by age, by multiplying the proportion of never married individuals in the unadjusted age group total with the adjusted age group total by gender (see appendix on the use of adjusted data). The NFHS data contains three survey waves from 1992 to 2006 of women between 15 and 45 years of age. Each woman reports her age, her partner's age, and the date of marriage. Figure 3 shows a (jittered) scatter plot of the marriage ages of women and their partners for all weddings that took place between 1963 and 1979. The final data set has 3301 marriages with average date 1973.3. ${ }^{21}$ In most marriages, the husband is older than the wife. While some people married under ten years, women marry mostly between 13 and 20 years and men between 16 and 30 years of age.

${ }^{21}$ Note that the sample is not representative of a given cohort or year, see below. 
Table 3. Sex Ratio and Rates of Permanent Celibacy, Karnataka

\begin{tabular}{|r|rrr|rr|}
\hline & \multicolumn{2}{|c|}{$\begin{array}{c}\text { Ratio of single } \\
\text { men to women }(\hat{r})\end{array}$} & \multicolumn{2}{c|}{ mever married } \\
& \multicolumn{2}{|c|}{ men } & women \\
\hline Ages & $2-49 / 2-29$ & $20-29 / 10-19$ & all ages & $50-55$ & $30-35$ \\
\hline 1911 & 1.516 & 0.652 & 1.444 & 3.3 & 2.0 \\
1931 & 1.529 & 0.647 & 1.440 & 2.0 & 1.4 \\
1971 & 1.336 & 0.518 & 1.291 & 1.6 & 1.3 \\
\hline
\end{tabular}

Census of India, 1901-1931, 1971, 1981.

Table 3 lists Karnataka's singles sex ratio $\hat{r}$ over time. I assume that both men and women enter the marriage market at age 2 and leave it at $I=29$ and $J=49$, reflecting the minimal and maximal marriage ages in the NFHS. Due to this unequal choice there are more single men than women; what matters for the argument here, however, is that both in 1911 and in 1931 the observed singles sex ratio $\hat{r}$ is more than 0.18 points higher than in 1971 , implying that men's market conditions improved substantially. By theorem 4.2, the steep decline of the singles sex ratio during the squeeze predicts an increase in conditional dowries, driven by lower meeting rates of women. The singles sex ratios for different age ranges in the second and third column confirm that the effect is robust. The table also lists the proportion of never married men aged 50-55 and women aged 30-35, showing that, just as in India as a whole, the proportion of men and women who do not marry is very small and has changed little throughout.

Figure 4 shows the histograms of the men's and women's singles distributions for 1911 and 1931 (averaged) and for 1971. The men's distribution exhibits only relatively small changes between the beginning and end of the squeeze, especially when comparing the unadjusted data. Moreover, most of the movement takes place before fifteen years of age. The women's singles age distribution, on the other hand, experienced a clear shift of probability mass from the age groups 0-5 and 5-10 to 15-20 years. The NFHS data has shown that girls rarely marry under the age of ten at the end of the marriage squeeze (1971 preferences). If we accept that $w_{71}(i) \gg w_{31}(i)\left(w_{11}(i)\right)$ for all $i \in[15,20]$, and $w_{71}(i) \approx w_{31}(i)\left(w_{11}(i)\right)$ for 
Figure 4. Women's and men's age distributions, average of 1911 and 1931 vs. 1971.
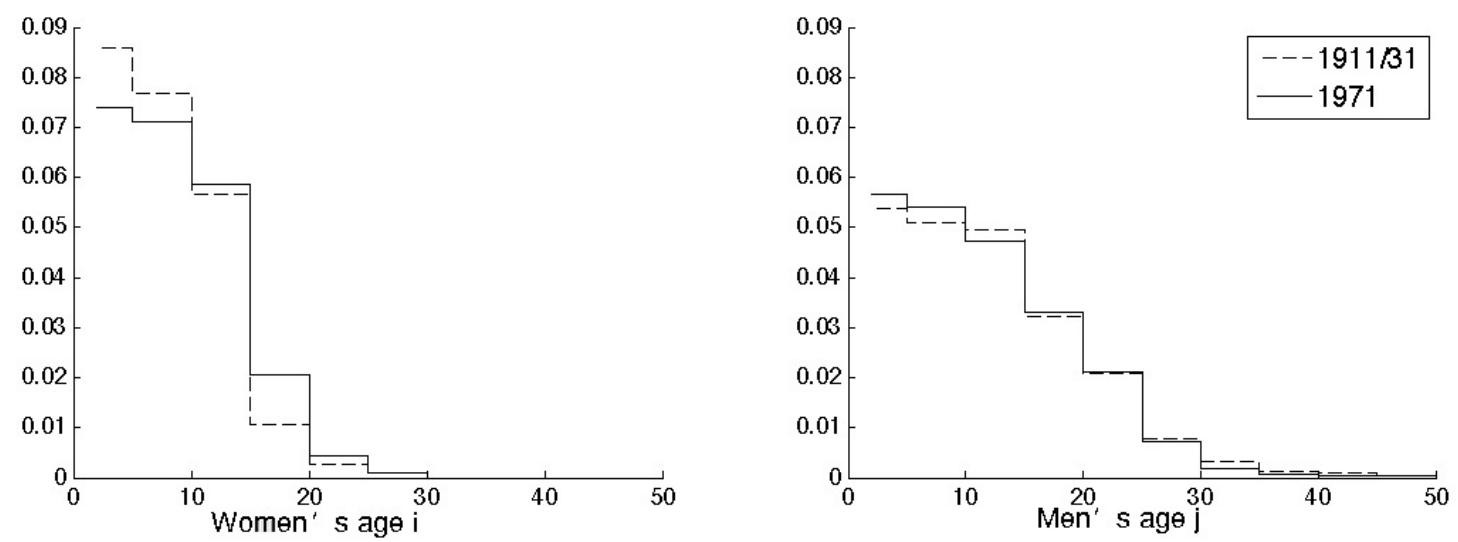

$i \in[10,15]$, then corollary 4.3 applies, suggesting that dowries conditional on partners' ages have increased from 1911/31 to 1971.

Together, we have

Observation 4.4. At the end of the marriage squeeze, the singles sex ratio has declined, and the women's singles age distribution puts more probability weight on women who actually marry (and whose net marriage surplus is therefore higher). Theorem 4.2 and corollary 4.3 therefore imply that conditional dowries have increased.

Observation 4.4 draws a first important conclusion about the effect of demographic change on dowries. The conditional dowry is a direct reflection of men's and women's relative value of participating in the marriage market. If that value declines for women and rises for men, surplus is redistributed from the women's to the men's side. The conditional dowry increase is equivalent to an increase in the price of marriage for women for a given match quality. Importantly, this would even hold if average dowries had at the same time decreased due to a change in the composition of observed marriages.

The effect of demographic change on average dowries, as well as on marriage ages, is of equal interest, but cannot be derived from this result alone. To quantify these effects and determine if the marriage squeeze has caused an inflation in average dowries I estimate the model in the next section. 


\section{GMm Estimation: Average Dowry and Marriage Age}

In what follows I will employ the 1971 data for a minimum-distance estimate of the payoff function $\pi$, and then use the estimated $\hat{\pi}$ and the data from 1911 and 1931 to calculate the value functions and marriage strategies from before the marriage squeeze. The results are used to compare average dowries and marriage ages before and after. As before, it must be assumed that the market is in a steady-state and that preferences are the same before and after the marriage squeeze. An advantage of the estimation is that it can account for changes in mortality, whereas the previous section only assumed a change in $g$. While the differences are small - most mortality improvements happened for children under 5 years of age - this aspect of demographic change can now also be part of the analysis. ${ }^{22}$

\subsection{Demographic Variables and moments for the estimation}

The estimation uses two sets of moments, from the NFHS and from the 1971 census. The time period of the model is assumed to be one year. The moments from the NFHS are the numbers of women at age $i$ who married a man at age $j$ as a proportion of all women who were at age $i$ between 1963 and 1979. If there was no attrition, these proportions would be representative even if the numbers of women at each age in the combined data set are not. However, since the NFHS is retrospective, it is biased by the fact that older women or women who married old husbands are more likely to be widowed or deceased before the survey takes place. To correct for this bias, each woman's observation is weighed by the inverse of the probability of death of husband and wife between the marriage date and the survey date, calculated again from the UN lifetables. The data is then grouped by the same age intervals as the census to yield moments

$$
\hat{M}=\left\{\hat{M}_{k, l}\right\} \text { for } k=2-4,5-9, \ldots, 25-29 \text { and } l=2-4,5-9, \ldots, 45-49 \text {. }
$$

The second set of moments is the counterpart to the singles distribution. Denote by $\hat{d}_{x(k)}$ the proportion of sex $x \in\{f, m\}$ individuals at age $k$, and by $\hat{d}_{m}$ the proportion of men in

${ }^{22}$ Mortality under age 1 and at ages 1-4 both halved. From age 5 on, the probability of dying decreased by 0.02 in each 5 -year age interval; this is an about $0.2 \%$ higher per-period chance of dying. 
the overall singles population. The empirical moments are $\hat{d}=\left\{\hat{d}_{f(2)}, \hat{d}_{f(3)}, \hat{d}_{f(4)}, \hat{d}_{f(5-9)}, \ldots \hat{d}_{f(20-24)} ; \hat{d}_{m(2)}, \hat{d}_{m(3)}, \hat{d}_{m(4)}, \hat{d}_{m(5-9)}, \ldots \hat{d}_{m(40-44)} ; \hat{d}_{m}\right\}$

All demographic parameters of the model are derived from total census population counts and from the UN life tables (appendix B). First, consider the equivalent of equations (2.1) and (2.2) for the female and male total populations. Assuming a population steady state, $\hat{s}_{i}=\frac{s_{i}}{1+g}$ is given by the ratio of $\hat{w}_{i} / \hat{w}_{i-1}$, where $\hat{w}_{i}$ is the proportion of the total female population at age $i$, so from the total population counts I can derive $\hat{s}$ and $\hat{z}$ for all ages. ${ }^{23}$ Alternatively, the annual probabilities of survival can be derived from the life tables. Assuming that the mortality rate within each 5-year age group is constant, $s_{i}$ for each age is given by $\left(1-{ }_{10} q_{5}\right)^{0.2}{ }^{24}$ The $\hat{s}$ and $\hat{z}$ are used in the estimation algorithm to calculate the steadystate singles distribution, and $s$ and $z$ enter the value functions. Since $g=\frac{s_{i}}{\hat{s}_{i}}-1$, the two alternative derivations can be used to calculate the average implied annual growth rate, yielding 1.43 and 1.45 percent for 1911 and 1931, and $2.33 \%$ for 1971 . This is approximately consistent with the population growth rates from the census. Finally, the birth sex ratio and survival rates until market entry $b \frac{z_{0}}{s_{0}}$ are obtained from the empirical singles distribution, using that in equilibrium $r=b \frac{z_{0}}{s_{0}} \frac{w_{1}}{m_{1}}$ (when $b \frac{z_{0}}{s_{0}}$ is calculated in this way it equals 1.039 in 1971).

\subsection{Estimation Assumptions And procedure}

The marriage payoff function is parameterized as

$$
\pi(i, j)=C+p_{1} i+p_{2} i^{2}+p_{3} j+p_{4} j^{2}+p_{5} i j
$$

where $C$ is a constant. The functional form implies that age preferences depend quadratically on the age of the wife and husband. At the same time, the optimal marriage age of one

\footnotetext{
${ }^{23}$ For grouped age categories I solve for a constant multiplier, e.g. $\hat{s}_{5}$ to $\hat{s}_{9}$ solve $\hat{w}_{(5-9)}=$ $\frac{\hat{s}}{1-\hat{s}}\left(1-\hat{s}^{5}\right) \hat{w}_{4}$.

${ }^{24}$ The notation ${ }_{n} q_{x}$ refers to the proportion of individuals who will die in the $x$-year age interval beginning at $n$. It is throughout assumed that mortality is independent from marital status, a simplification given maternal mortality.
} 
partner clearly depends on that of the other (e.g. on their age difference). This is captured by parameter $p_{5}$. If this parameter is positive partners' ages are complements. Note that marriage strategies, determined by $S(i, j)$, are invariant to linear transformations of $\pi$ and $(B, G)$. The constant $C$ and parameters $p$ are therefore identified up to the sign of $C$. $C$ is set to -10 , amounting to the assumption that the payoff from remaining single at 30 and 50 , respectively, is higher than that of marrying at ages $(2,2)$.

Identification for the parameters comes from two sources. First, the probability of marrying at $i$ determines $\varphi_{i}$, or the change in the age distribution $w$ between $i$ and $i+1$. The same holds for the men's side; the "size" of the set of $i$ that $j$ marries determines $\psi_{j}$. These are given by the empirical moments $\hat{d}$. At the same time, the exact "location" of this set within ages $1, \ldots, I$ is determined by marriage behavior, observed in the $\hat{M}$. Given the man's age $j$, the shape of his matching set depends on the woman's age through $p_{1}+p_{5} j$ and $p_{2}$ (and his outside option). Conversely, the women's matching sets are determined by $p_{3}, p_{5} i$ and $p_{4}$. Note that the parameters are identified only up to a small neighborhood around them, because the model is discrete: in a pure strategy equilibrium, an $\epsilon$ variation of the payoff function around a given set of parameters will have no effect on marriage decisions, so the moments are the same. But marriage probabilities and marriage ages are unaffected by this, and checks on the results show that varying the estimated parameter vector $\hat{p}$ within the relevant range $(< \pm 0.0001)$ has a negligible effect on average dowry payments calculated from the estimates.

The Nash bargaining parameter is set to $\theta=0.5$, and the discount factor to $\delta=0.9596 .^{25}$ The meeting rates $\lambda_{w}$ and $\lambda_{m}$ are assumed to take the following form:

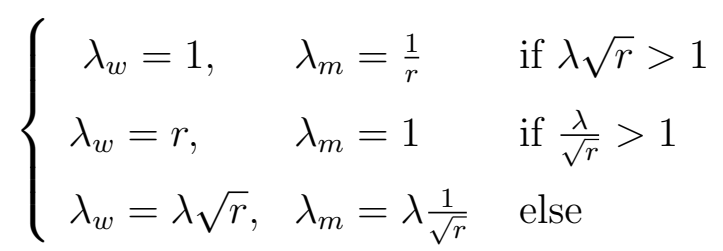

for $\lambda=0.8$. In effect there is a "base" meeting rate of 0.8 , which is then modulated symmetrically by the square root of $r$ (or the inverse of $r$ ). With this formulation, the $\lambda$ functions are continuous and symmetric for any $r \in[0.64,1.5625]$.

\footnotetext{
${ }^{25} \delta=\frac{1}{1+r}$ where $r$ is the annual redemption yield of government of India securities.
} 
The choice of functional form and the other assumptions were made with a view to making the model as symmetric as possible. This may not be entirely accurate with respect to the realities of the Indian marriage market, but it ensures that any asymmetry in the results, especially in marriage transfers, is not introduced artificially.

The estimation routine proceeds by guessing parameters $p$ and finding the equilibrium matching set and age distributions. Given parameters $p$ and a singles distribution, the value functions $B$ and $G$ are unique and can be found by iteration (lemma 2.2). With the empirical singles distribution $(\hat{m}, \hat{w}, \hat{r})$ as a starting point, the algorithm calculates the (unique) value functions and an initial matching matrix $A$. This matrix, together with the exogenous demographic parameters and the $\lambda$ functions, is used to iterate over $m$ and $w$ to find a new steady state singles distribution using equations (2.1)-(2.4). From here on the process is repeated until the matching matrix converges. ${ }^{26}$ The resulting equilibrium age distribution $(m, w, r)$ and matching matrix $A$ are used to calculate the theoretical moments $\{M, d\}$. The objective function is given by

$$
(\hat{V}-V)^{\prime}(\hat{V}-V)
$$

with $\hat{V}$ and $V$ the stacked vectors of moments $(\hat{d}, \hat{M})$ and $(d, M) \cdot{ }^{27}$

The resulting estimate $\hat{p}$ can then be used for counterfactuals. With demographic information on $g, s$ and $z$ for 1911 and 1931, the same algorithm as above is applied to find the value functions and equilibrium singles distributions for these years. Note that the only sources of exogenous change between 1911/1931 and 1971 are the different growth rate and mortalities that the marriage market is subjected to before and after the marriage squeeze,

\footnotetext{
${ }^{26}$ Since I have not formally shown that $m$ an $w$ are contractions, it is in theory possible that there are several steady-state singles distributions, but in practice the routine converges reliably. In addition, despite potential multiplicity of equilibria, with different starting age distributions the procedure always converged to the same equilibrium. The program can be extended to allow for mixed equilibria, but due to computing capacity limits I restrict the search to pure-strategy equilibria.

${ }^{27} \mathrm{~A}$ unity weighting matrix was chosen after a two-step procedure to get empirical (variance) weights proved too time-consuming.
} 
TABle 4. Estimation Results: Parameters of $\pi$

\begin{tabular}{|c|c|c|c|c|c|c|c|c|}
\hline & & $p_{1}$ & $p_{2}$ & $p$ & 3 & $p$ & $P_{4}$ & $p_{5}$ \\
\hline Est. & & 257 & -0.161 & 1.6 & 18 & -0 & 083 & 0.254 \\
\hline CI $95 \%$ & $(-0.279$ & $-0.131)$ & $(-0.193-0.117)$ & $(1.326$ & $1.908)$ & $(-0.100$ & $-0.060)$ & $\left(\begin{array}{ll}0.194 & 0.301\end{array}\right)$ \\
\hline
\end{tabular}

CI: $95 \%$ confidence intervals from bootstrapping procedure.

FiguRE 5. Payoff function $\pi$ for $\pi \geq 0$.
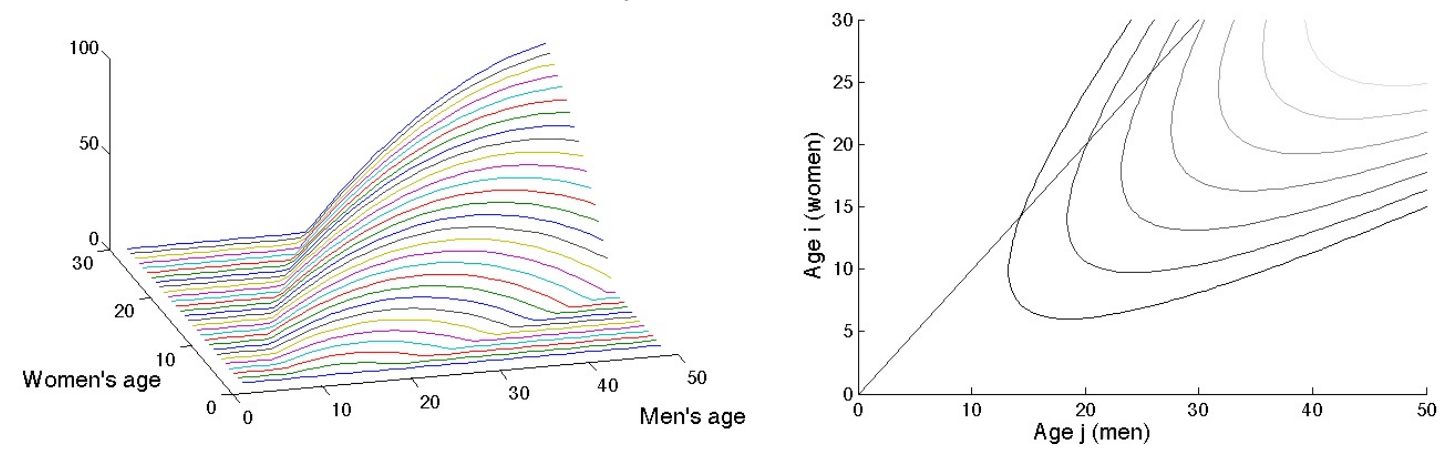

embodied in $s, z, \hat{s}$ and $\hat{z}$. To account for the sampling variance of the estimates, I use a bootstrap procedure to draw new samples from the NFHS data and repeat the estimation for those (using the unchanged census data each time). In the results below I report the 95\% confidence intervals obtained from the bootstrap.

\subsection{Results}

The parameter estimates are reported in table 4 . Figure 5 depicts the resulting payoff function. Observe that the age of the woman by itself has a negative effect on the marriage payoff, but the interaction term $p_{5}$ makes the overall effect positive as long as the man is at least about a third older than her. The man's age positively affects marriage payoffs.

Table 5 reports the calculated marriage ages and dowries from the estimation (1971) and the counterfactuals (1911 and 1931). The top half of the table gives the mean ages and average age gap at marriage as calculated from the equilibria under $\hat{\pi}$. The last column reports the absolute change of the marriage age difference from 1911 and 1931 to 1971. According to the estimates the age gap at marriage has significantly fallen from the beginning to the end of the squeeze, from 8.26 (8.28) to 7.87 years, with an absolute change of 0.39 
TABle 5. Estimation Results: Dowries and Marriage Ages

\begin{tabular}{|c|c|c|c|c|}
\hline Marriage age & women & men & difference & abs. change to ' 71 \\
\hline \multirow[t]{2}{*}{1911} & 16.736 & 24.998 & 8.262 & -0.388 \\
\hline & $\left(\begin{array}{ll}16.459 & 17.800\end{array}\right)$ & $\left(\begin{array}{ll}24.343 & 25.754\end{array}\right)$ & $\left(\begin{array}{ll}7.757 & 8.265\end{array}\right)$ & $(-0.519 \quad-0.166)$ \\
\hline \multirow[t]{2}{*}{1931} & 16.775 & 25.055 & 8.280 & -0.406 \\
\hline & $\left(\begin{array}{ll}16.521 & 17.862\end{array}\right)$ & $(24.398 \quad 25.895)$ & $\left(\begin{array}{ll}7.779 & 8.285\end{array}\right)$ & $\left(\begin{array}{ll}-0.649 & -0.153\end{array}\right)$ \\
\hline \multirow[t]{2}{*}{1971} & 17.583 & 25.457 & 7.874 & \multirow[t]{2}{*}{ - } \\
\hline & $\left(\begin{array}{ll}17.441 & 18.625\end{array}\right)$ & $\left(\begin{array}{ll}25.128 & 26.169\end{array}\right)$ & $\left(\begin{array}{ll}7.253 & 7.874\end{array}\right)$ & \\
\hline (Sekher et al. 1971) & 17.79 & 25.24 & 7.45 & - \\
\hline Dowries & average & lowest & highest & $\%$ change to ' 71 \\
\hline \multirow[t]{2}{*}{1911} & 8.678 & -2.386 & 11.629 & 0.209 \\
\hline & $\left(\begin{array}{ll}5.512 & 14.92\end{array}\right)$ & $\left(\begin{array}{ll}-3.104 & -2.011\end{array}\right)$ & $\left(\begin{array}{ll}8.560 & 19.732\end{array}\right)$ & $0.479)$ \\
\hline \multirow[t]{2}{*}{1931} & 8.601 & -2.446 & 11.603 & 0.22 \\
\hline & $\left(\begin{array}{ll}5.498 & 14.771\end{array}\right)$ & $\left(\begin{array}{ll}-3.176 & -2.076\end{array}\right)$ & $\left(\begin{array}{ll}8.555 & 19.653\end{array}\right)$ & $0.483)$ \\
\hline \multirow[t]{2}{*}{1971} & 10.496 & -1.856 & 13.245 & \multirow[t]{2}{*}{ - } \\
\hline & $\left(\begin{array}{ll}8.039 & 18.002\end{array}\right)$ & $\left(\begin{array}{ll}-2.366 & -1.507\end{array}\right)$ & (10.188 22.537) & \\
\hline
\end{tabular}

$95 \%$ confidence intervals from bootstrapping procedure in parentheses.

(0.41) years. The decrease comes about partly because women delay marriage, and partly because men marry slightly earlier. The last line reproduces the Sekher et al. estimates of male and female marriage ages in small print, showing that my estimates match their results closely. $^{28}$

The estimation does not replicate the full increase in marriage age for women, and consequently it also does not capture the entire change in the age difference at marriage. One

${ }^{28}$ Note that their marriage ages are estimated from the numbers of married and unmarried individuals in every age group as reported in the census. The census assumes that all children under ten are unmarried, while according to the NFHS 2.2 percent of women and 0.5 percent of husbands were under 10 at their wedding. 
possible reason for the discrepancy is that the present model does not account for widower remarriage. As Bhat and Halli (1999) point out, women in India remain usually unmarried after the death of their husbands, whereas men often remarry, potentially inducing an additional marriage squeeze when women's mortality declines and fewer widowers return to the marriage market. In 1971, very few men are widowed before their 50s, so this is not an important factor in the marriage market. Before the squeeze, the death of a spouse is more likely; here the number of widowers adds about $4 \%$ to the overall number of single men up to age 50. But this is still a fairly small share of the market, and widowerhood is a rare event even then. ${ }^{29}$ The results might therefore indicate that the marriage age gap was reduced by the squeeze, but that there was an additional upward shift in women's marriage age due to other factors.

The lower half of the table reports the calculations for dowries. The first three columns show the average dowry paid in a given year and the minimal and maximal payments between different age pairings $(i, j)$. Interestingly, positive and negative payments (brideprices) coexist, depending on the partners' ages. This is consistent with anecdotal reports on dowries. Since the estimated dowries are expressed in utility units, which are only informative in relative terms, the last column reports the percentage change in average dowries from 1911 and 1931 to 1971 . There is a significant increase in the average dowry of about $20 \%$ in real terms. Assuming that utility is linear in money, we can use the net dowries paid in Karnataka marriages between 1963 and 1979 in the NCAER data set, and the total income of those same 119 households, to gauge the size of the change. The average dowry for those marriages was Rs. 23,212, and their mean annual household income at the time of the survey

\footnotetext{
${ }^{29}$ In the model used here, $\pi$ reflects the present value of all payoffs during marriage, and the model remains approximately accurate if there is the possibility of remarriage, but the probability of being widowed is very low. To estimate an equilibrium where remarriage is likely, the model must specify in addition when the marriage payoffs actually occur, and the present value has to take in account payoffs in the current marriage as well as the possibility of the partner's death and a return into the marriage market.
} 
Rs. 21,486 (both in 1984 Rs.). The estimation would then imply that the average dowry has increased from $89 \%$ to $108 \%$ of annual household income.

Besides dowry and marriage ages, one may want to compare overall welfare between the two equilibria and assess the welfare loss due to search frictions. Table 6 shows the value of search at market entry, given by $B_{0}$ and $G_{0}$, as well as the average value of search per person for each new generation, using that the number of men at age 1 equals $b \frac{z_{0}}{s_{0}}$ times the number of women at age 1 . The table also reports the social planner expected payoffs and optimal marriage ages (the combination $(i, j)$ which maximizes the average expected payoff). This is calculated in a similar manner as the expected average per-person value of marriage, but assuming there is a social planner who can decree that all men and women marry at the payoff-maximizing ages. The payoff to marriage at birth if all couples marry at ages $(i, j)$ is $0.5 q_{w} \delta^{i} \pi(i, j)$ for a woman and $0.5 q_{w} \delta^{i} \pi(i, j)$ for a man, where $q_{w}$ and $q_{m}$ represent the individual woman's or man's probability of marriage. Using the growth rate 0.0233 from above for 1971 (0.0143 for 1911 and 0.0145 for 1931) and the relationship $M_{1}=b \frac{z_{0}}{s_{0}} W_{1}$, the ratio between men and women at each age combination can be calculated, and assuming that all on the short side of the market marry, this provides the probability of marriage for the other side.

The table shows that the marriage squeeze reduces the value of search for women by at least $14 \%$, while it raises that for men by $26 \%$ or more. The highly beneficial effect of demographic change for men, induced by delayed marriage and a weaker market position for women, means that the average per-person value actually increases.

Under a social planner regime, marriage ages would be much higher than they actually are. The optimal age gap would still be large, but it optimally decreases slightly under the marriage squeeze to keep women's probability of marriage high. As a consequence, the maximal possible per-person social surplus is almost unchanged by the marriage squeeze. The comparison between actual and social-planner payoffs (assuming no transfers) reveals that the search frictions induce not only a large reduction in welfare, but also a substantial redistribution of marriage payoffs from women to men. This means that men benefit from the search frictions and the resulting high dowry payments, whereas women would prefer 
TABLE 6. Welfare comparison.

\begin{tabular}{rrrrrrrrr}
\hline \hline & \multicolumn{3}{c}{ Value of search } & \multicolumn{5}{c}{ Social planner solution } \\
& B & G & avg. p.p. & marr. ages & $q_{w}$ & exp. payoff women & men & avg. p.p. \\
\hline 1911 & 2.28 & 6.59 & 4.36 & $(29,42)$ & 0.77 & 9.20 & 6.96 & 8.12 \\
1931 & 2.34 & 6.57 & 4.39 & $(29,42)$ & 0.78 & 9.32 & 6.96 & 8.17 \\
1971 & 1.96 & 8.33 & 5.21 & $(29,40)$ & 0.81 & 9.04 & 7.12 & 8.07 \\
\hline
\end{tabular}

a social planner regime despite lower marriage rates, highlighting the pressure on women brought on by the greater urgency of their search.

\section{Conclusion}

This paper developed a model of the marriage market in India and analyzed its predictions for the change in dowries and marriage ages during the marriage squeeze. The model assumes that marriage preferences depend on the partners' ages, and that there are frictions in the search for a marriage partner. Within this framework, the changes to the singles distribution as a consequence of the squeeze imply increased dowries conditional on age. In addition, the estimation results suggest that average dowries have risen as well, while the age gap at marriage has decreased at the same time. These results do not rule out possible other (additional) reasons for the observed changes, but they lend strong support to the hypothesis that both marriage age changes and dowry inflation in India were caused in part by demographic change. The adverse welfare effects of the marriage squeeze on women can explain the universal perception of increased pressure on their side of the market and the renewed urgency of the dowry debate in 1960-80, leading to the Dowry Prohibition Act in 1961 and the insertion of a marital cruelty act with specific reference to dowry harassment into the criminal code in 1983 (IPC 498A).

Population growth in India leveled off in the 1980's and has since begun to decline. Moreover, the sex ratio is shifting due to the greater availability of abortion and the use of sex selection in favor of boys (e.g. Almond and Edlund (2008)). The same development has been observed in other countries with a strong preference for sons, notably China, which 
is today experiencing a serious shortage of women (Das Gupta and Shuzhuo (1997)). We would consequently expect dowries to halt their rise, and the available data supports that conjecture. In addition, the age gap at marriage may eventually stabilize or begin to increase again.

However, as long as "an older unmarried daughter is a tremendous misfortune with large social and economic costs" (Bloch and Rao (2002)), the overall demand for husbands in India will be inelastic to prices, and dowries will be susceptible to demographic shocks. The link between marriage squeeze, dowry inflation, and age preferences therefore implies a continued role for public policy. The Dowry Prohibition Act, difficult to enforce, had little effect on the dowry practice, suggesting that efforts to abolish dowry might be more successful if they focus on altering rigid age and marriage preferences and giving women options that are independent of their traditional role as wives.

On a more general level, the findings of this paper emphasize the very important role that age preferences and demographics play for the marriage market. Their powers came to bear particularly strongly in India, which has seen extraordinary demographic change in a comparatively short time span, but the effects of demographic imbalance can be seen elsewhere as well, for example in increased savings by parents of sons in China (Wei and Zhang (2011)) and in the lower partner quality for women in France after WWI (Abramitzky et al. (2011)). India's dowry problem thus highlights a force in the marriage market that has only recently received renewed attention from economists. 


\section{Appendix A. Omitted Proofs}

Proof of Lemma 2.2: $\quad$ Let $X=[0, \bar{B}]^{I} \times[0, \bar{G}]^{J}$ with the sup norm, and define a map $T: X \rightarrow X$ so that

$$
\begin{aligned}
T(B, G)_{i} & =\delta s_{i+1} B_{i+1}+\sum_{j=1}^{J} P_{i j} \theta \alpha_{i j}\left[\pi(i, j)-\delta s_{i+1} B_{i+1}-\delta z_{j+1} G_{j+1}\right], i=1, \ldots, I, \text { and } \\
T(B, G)_{I+j} & =\delta z_{j+1} G_{j+1}+\sum_{i=1}^{I} Q_{j i} \theta \alpha_{i j}\left[\pi(i, j)-\delta s_{i+1} B_{i+1}-\delta z_{j+1} G_{j+1}\right], j=1, \ldots, J
\end{aligned}
$$

Consider two sets of value functions $(B, G)$ and $(\hat{B}, \hat{G})$ in $X$, and let $\alpha_{i j}$ denote a positive net marriage surplus for $B$ and $G$. Define $\epsilon=\max \left\{\max _{i}\left|B_{i}-\hat{B}_{i}\right|, \max _{j}\left|G_{j}-\hat{G}_{j}\right|\right\}$. Without loss of generality, assume that $T(B, G)_{i} \geq T(\hat{B}, \hat{G})(i)$. It must be that

$$
T(\hat{B}, \hat{G})_{i} \geq \delta s_{i+1} \hat{B}_{i+1}+\sum_{j=1}^{J} P_{i j} \theta \alpha_{i j}\left[\pi(i, j)-\delta s_{i+1} \hat{B}_{i+1}-\delta z_{j+1} \hat{G}_{j+1}\right]
$$

since $\alpha$ describes the optimal behavior for $B$ and $G$, not $\hat{B}$ and $\hat{G}$. Thus,

$$
\begin{aligned}
T(B, G)_{i}-T(\hat{B}, \hat{G})_{i} \leq & \delta s_{i+1}\left(B_{i+1}-\hat{B}_{i+1}\right)+ \\
& \sum_{j=1}^{J} P_{i j} \theta \alpha_{i j}\left[\delta s_{i+1}\left(\hat{B}_{i+1}-B_{i+1}\right)+\delta z_{j+1}\left(\hat{G}_{j+1}-G_{j+1}\right)\right] \\
= & \left(1-\sum_{j=1}^{J} P_{i j} \theta \alpha_{i j}\right) \delta s_{i+1}\left(B_{i+1}-\hat{B}_{i+1}\right)+ \\
& \sum_{j=1}^{J} P_{i j} \theta \alpha_{i j} \delta z_{j+1}\left(\hat{G}_{j+1}-G_{j+1}\right) \\
< & \epsilon .
\end{aligned}
$$

The last inequality holds since the effective discount factor is less than 1 . The map $T$ is a contraction, and has a unique fixed point (Banach).

Proof of Theorem 2.3: $\quad$ First observe that $\Phi$ and $\Psi$ are bounded, so that $w_{1} \in$ $S_{w}=\left[\frac{s_{1}^{I-1}\left(s_{1}-1\right)}{s_{1}^{I}-1}, 1\right]$ and $m_{1} \in S_{m}=\left[\frac{s_{1}^{J-1}\left(s_{1}-1\right)}{s_{1}^{J}-1}, 1\right]$ (using that $z_{1}=s_{1}$ ). The lower bound of these intervals is strictly positive. The sex ratio is therefore confined to $S_{r}=$ $\left[\frac{b s_{0}}{s_{1}^{a}} \frac{s_{1}^{I-1}\left(s_{1}-1\right)}{s_{1}^{I}-1}, \frac{b s_{0}}{s_{1}^{a}} \frac{s_{1}^{J}-1}{s_{1}^{J-1}\left(s_{1}-1\right)}\right]$. Let $\mathbb{L}^{n}$ be the unit simplex of dimension $n$. We can now define

$$
X \equiv\left(\left(S \times \mathbb{R}^{I-1}\right) \cap \mathbb{L}^{I}\right) \times\left(\left(S^{\prime} \times \mathbb{R}^{J-1}\right) \cap \mathbb{L}^{J}\right) \times S_{r} \times[0,1]^{I \times J}
$$


as the space in which the age distributions $(w, m, r)$ and matrices $A$ live. It is closed, bounded, and convex.

Define $F: X \rightarrow X$ on that space as follows. $F_{i}$ for $i=1, \ldots, I$ is given by the righthand side of equations 2.3 and 2.1 , and $F_{I+j}$ for $j=1, \ldots, J$ is described by equations 2.2 and 2.4. $F_{I+J+1}$ is the right-hand side of 2.5. In other words, the first $I+J+1$ terms of $F$ just create new singles distributions from given $w, m$ and $r$ and strategy matrix $A$. The remaining $I \times J$ terms of $F$ are the new marriage indicators, obtained from the by lemma 2.2 unique - value functions for $d$. $F$ is single-valued, except at points where $\pi(i, j)-\delta s_{i+1} B_{i+1}-\delta z_{j+1} G_{j+1}=0$, where $\alpha_{i j}$ can take values between 0 and 1 . The image of a point in $X$ under $F$ is non-empty, closed, and convex, and $F$ is upper hemi-continuous, since $P$ and $Q$ are continuous. The map therefore has a fixed point, and this fixed point constitutes a marriage market equilibrium.

Proof of Claim p. 27: It must be shown that $\lim _{n} B_{n}$ equals $\boldsymbol{B}_{d^{* *}}(G)$, or equivalently that $\lim \boldsymbol{B}_{d^{* *}}\left(G_{n}\right)=\boldsymbol{B}_{d^{* *}}\left(\lim G_{n}\right)$. In the remainder of the proof, the $d^{* *}$ index is suppressed for better readability.

The proof is by induction on $i$. First, note that $\lim \boldsymbol{B}\left(G_{n}\right)_{I+1}=\boldsymbol{B}(G)_{(I+1}=0$. The inductive step is to show that, if $\lim \left[\boldsymbol{B}\left(G_{n}\right)_{i+1}\right]=\boldsymbol{B}(G)_{i+1}$, then $\lim \left[\boldsymbol{B}\left(G_{n}\right)_{i}\right]=\boldsymbol{B}(G)_{i}$ as well:

$$
\begin{aligned}
\lim \left[\boldsymbol{B}\left(G_{n}\right)_{i}\right] & =\lim \left[\delta s_{i+1} \boldsymbol{B}\left(G_{n}\right)_{i+1}+\sum_{j=1}^{J} P_{i j} \theta \max \left[0, \pi(i, j)-\delta s_{i+1} \boldsymbol{B}\left(G_{n}\right)_{i+1}-\delta z_{j+1} G_{n, j+1}\right]\right] \\
& \left.=\delta s_{i+1} \boldsymbol{B}(G)_{i+1}+\sum_{j=1}^{J} P_{i j} \theta \max \left[0, \pi(i, j)-\delta s_{i+1} \boldsymbol{B}(G)_{i+1}-z_{j+1} G_{j+1}\right)\right]=\boldsymbol{B}(G)_{i} .
\end{aligned}
$$

Proof of Theorem 4.2: In view of the previous results, to prove (1) it only needs to be shown that $\boldsymbol{B}_{r^{*}}(G) \leq \boldsymbol{B}_{r}(G)$ and $\boldsymbol{G}_{r^{*}}(B) \geq \boldsymbol{G}_{r}(B)$ for $r^{*}<r$, with one of the two strict. The proof is very similar to that of lemma 4.1. Fix $G$ and observe that $\lambda_{w}\left(r^{*}\right)<\lambda_{w}(r)$. We want to show that $\boldsymbol{B}_{r^{*}}(G)_{i}<\boldsymbol{B}_{r}(G)_{i}$ for all $i$. By contradiction, suppose $i$ is the highest age at which $\boldsymbol{B}_{r^{*}}(G)_{i}>\boldsymbol{B}_{r}(G)_{i}$. Let $\hat{\alpha}_{i j}$ be the optimal marriage decisions for $\boldsymbol{B}_{r^{*}}(G)$. But then

$$
\boldsymbol{B}_{r^{*}}(G)_{i}=\delta s_{i+1} \boldsymbol{B}_{r^{*}}(G)_{i+1}+\sum_{j=1}^{J} \lambda_{w}\left(r^{*}\right) m_{j} \hat{\alpha}_{i j} \theta\left[\pi(i, j)-\delta s_{i+1} \boldsymbol{B}_{r^{*}}(G)_{i+1}-\delta z_{j+1} G_{j+1}\right]
$$




$$
\begin{aligned}
& <\delta s_{i+1} \boldsymbol{B}_{r^{*}}(G)_{i+1}+\sum_{j=1}^{J} \lambda_{w}(r) m_{j} \hat{\alpha}_{i j} \theta\left[\pi(i, j)-\delta s_{i+1} \boldsymbol{B}_{r^{*}}(G)_{i+1}-\delta z_{j+1} G_{j+1}\right] \\
& =\left(1-\sum_{j=1}^{J} \lambda_{w}(r) m_{j} \hat{\alpha}_{i j} \theta\right) \delta s_{i+1} \boldsymbol{B}_{r^{*}}(G)_{i+1}+\sum_{j=1}^{J} \lambda_{w}(r) m_{j} \hat{\alpha}_{i j} \theta\left[\pi(i, j)-\delta z_{j+1} G_{j+1}\right] \\
& \leq\left(1-\sum_{j=1}^{J} \lambda_{w}(r) m_{j} \hat{\alpha}_{i j} \theta\right) \delta s_{i+1} \boldsymbol{B}_{r}(G)_{i+1}+\sum_{j=1}^{J} \lambda_{w}(r) m_{j} \hat{\alpha}_{i j} \theta\left[\pi(i, j)-\delta z_{j+1} G_{j+1}\right] \\
& \leq \boldsymbol{B}_{r}(G)_{i} .
\end{aligned}
$$

A similar argument holds for $\boldsymbol{G}$ if $\lambda_{m}\left(r^{*}\right)>\lambda_{m}(r)$. Since $r^{*}<r$, one of the two must hold.

To show (2) it only needs to be shown that $\boldsymbol{G}_{w}(B)_{j} \leq \boldsymbol{G}_{w^{*}}(B)_{j}$ for all $j$. By contradiction, suppose $j$ is the highest age at which $\boldsymbol{G}_{w}(B)_{j}>\boldsymbol{G}_{w^{*}}(B)_{j}$. Let $\alpha_{i j}$ be the optimal marriage decisions for $\boldsymbol{G}_{w^{*}}(B)_{j}$. But then

$$
\begin{aligned}
\boldsymbol{G}_{w}(B)_{j} & =\left(1-\sum_{i=1}^{I} \lambda_{m} w_{i} \alpha_{i j} \theta\right) \delta z_{j+1} \boldsymbol{G}_{w}(B)_{j+1}+\sum_{i=1}^{I} \lambda_{m} w_{i} \alpha_{i j} \theta\left[\pi(i, j)-\delta s_{i+1} B_{i+1}\right] \\
& \leq\left(1-\sum_{i=1}^{I} \lambda_{m} w_{i} \alpha_{i j} \theta\right) \delta z_{j+1} \boldsymbol{G}_{w^{*}}(B)_{j+1}+\sum_{i=1}^{I} \lambda_{m} w_{i} \alpha_{i j} \theta\left[\pi(i, j)-\delta s_{i+1} B_{i+1}\right] \\
& =\delta z_{j+1} \boldsymbol{G}_{w^{*}}(B)_{j+1}+\sum_{i=1}^{I} \lambda_{m} w_{i} \alpha_{i j} \theta\left[\pi(i, j)-\delta z_{j+1} \boldsymbol{G}_{w^{*}}(B)_{j+1}-\delta s_{i+1} B_{i+1}\right] \\
& \leq \delta z_{j+1} \boldsymbol{G}_{w^{*}}(B)_{j+1}+\sum_{i=1}^{I} \lambda_{m} w_{i}^{*} \alpha_{i j}^{*} \theta\left[\pi(i, j)-\delta z_{j+1} \boldsymbol{G}_{w^{*}}(B)_{j+1}-\delta s_{i+1} B_{i+1}\right] \\
& =\boldsymbol{G}_{w^{*}}(B)_{j}
\end{aligned}
$$

The proof of Corollary 4.3 is similar to the proof for part (2) of theorem 4.2 and is omitted.

\section{Appendix B. UN lifetables And ADJusted CEnsus Data}

Using the life table, the development of each age group of the 1971 population can be simulated and compared with the next higher age bracket. Assuming a steady state, the simulated should be larger than the original population by roughly the same growth factor in each age group. This is not the case, and could at first blush indicate that the steady-state assumption is faulty; however, comparing the 1971 census with that from 1981 shows that within each age group growth lied between 1.7 and 3.4 percent annually in the 10 years, 
TABLE 7. Probability of dying per age interval $\left({ }_{n} q_{x}\right)$

\begin{tabular}{|r|ll|ll|}
\hline & $1911 / 31$ & & 1971 & \\
age & males & females & males & females \\
\hline 0 & 0.2268 & 0.20275 & 0.12967 & 0.13704 \\
1 & 0.20238 & 0.20976 & 0.09196 & 0.10603 \\
5 & 0.04734 & 0.05278 & 0.02425 & 0.02927 \\
10 & 0.01901 & 0.02254 & 0.01178 & 0.01351 \\
15 & 0.02154 & 0.03321 & 0.01292 & 0.01824 \\
20 & 0.0252 & 0.04043 & 0.01445 & 0.02275 \\
25 & 0.03005 & 0.04178 & 0.01770 & 0.02708 \\
30 & 0.03718 & 0.04697 & 0.02143 & 0.02922 \\
35 & 0.04758 & 0.05044 & 0.02972 & 0.03170 \\
40 & 0.06325 & 0.05583 & 0.04167 & 0.03722 \\
45 & 0.08465 & 0.06743 & 0.06368 & 0.04994 \\
50 & 0.11706 & 0.09613 & 0.09246 & 0.07305 \\
55 & 0.15488 & 0.13962 & 0.13955 & 0.11337 \\
60 & 0.21659 & 0.20267 & 0.19527 & 0.16724 \\
65 & 0.29286 & 0.27633 & 0.26502 & 0.24393 \\
\hline
\end{tabular}

Sources: 1911-31: model lifetables from United Nations (1982), life expectancy at birth 35 yrs. 1971: lifetable for India 1971-76 (United Nations (1986)).

reasonably close to a constant growth rate. This suggests that there is age misreporting, a fact also acknowledged in the census documentation. The estimation therefore uses adjusted age data as supplied by the census, which gives a more consistent picture for the population development between 1971 and 1981.

\section{REFERENCES}

Ran Abramitzky, Adeline Delavande, and Luis Vasconcelos. Marrying up: the role of sex ratio in assortative matching. American Economic Journal: Applied Economics, 3:124157, July 2011.

S.N. Agarwala. The age at marriage in India. Population Index, 23(2):96-107, April 1957. 
Douglas Almond and Lena Edlund. Son-biased sex ratios in the 2000 United States Census. Proceedings of the National Academy of Science, 105(15):5681-5682, April 2008.

Attila Ambrus and Erica Field. Early marriage, age of menarche, and female schooling attainment in Bangladesh. Journal of Political Economy, 116(5):881-930, 2008.

Siwan Anderson. Why dowry payments declined with modernization in europe but are rising in India. Journal of Political Economy, 111(2):269-310, 2003.

Siwan Anderson. The economics of dowry and brideprice. Journal of Economic Perspectives, 21(4):151-174, 2007a.

Siwan Anderson. Why the marriage squeeze cannot cause dowry inflation. Journal of Economic Theory, 137(1):140-152, 2007b.

Kakoli Banerjee. Marriage change in rural India, 1921-1981. The History of the Family, An International Quarterly, 3(1):63-94, 1998.

Theodore C. Bergstrom and David Lam. The effects of cohort size on marriage markets in twentieth century Sweden. In Tommy Bengtsson, editor, The family, the market and the state in industrialized countries. Oxford University Press, 1989a.

Theodore C. Bergstrom and David Lam. The two-sex problem and the marriage squeeze in an equilibrium model of marriage markets. unpublished, 1989b.

P. N. Mari Bhat. Mortality and fertility in India, 1881-1961: a reassessment. In India's Historical Demography, pages 73-118. Curzon Press, London, 1989.

P. N. Mari Bhat and Shiva S. Halli. Demography of brideprice and dowry: Causes and consequences of the Indian marriage squeeze. Population Studies, 53(2):129-148, 1999.

Michael S. Billig. The marriage squeeze on high-caste Rajasthani women. Journal of Asian Studies, 50(2):341-360, 1991.

Michael S. Billig. The marriage squeeze and the rise of groomprice in India's Kerala state. Journal of Comparative Family Studies, 13(2):197-216, 1992.

Francis Bloch and Vijayendra Rao. Terror as a bargaining instrument: a case study of dowry violence in rural India. American Economic Review, 92(4):1029-1043, 2002.

Maristella Botticini and Aloysius Siow. Why dowries? American Economic Review, 93(4): 1385-1398, 2003. 
J.C. Caldwell, P.H. Reddy, and Pat Caldwell. The causes of marriage change in South India. Population Studies, 37(3):343-361, 1983.

Lionel Caplan. Bridegroom price in urban India: Class, caste and 'dowry evil' among Christians in Madras. Man, 19(2):216-233, June 1984.

Ansley Coale. Excess female mortality and the balance of the sexes in the population: An estimate of the number of "missing females". Population and Development Review, 17(3): 517-523, September 1991.

Melvyn Coles and Adrian Masters. Retraining and long-term unemployment in a model of unlearning by not doing. European Economic Review, 44:1801-1822, 2000.

Monica Das Gupta and Li Shuzhuo. Gender bias and the "marriage squeeze" in China, South Korea and India 1920-1990: the effects of war, famine and fertility decline. Working paper, (97.05), 1997.

Premchand Dommaraju. Marriage age and fertility dynamics in India. DHS Working Paper, 52, August 2008.

Tim Dyson, Robert Cassen, and Leela Visaria. Twenty-first century India: population, economy, human development, and the environment. Oxford University Press, 2004.

Lena Edlund. The price of marriage: net versus gross flows and the South Asian dowry debate. Journal of the European Economic Association, 4(2-3):542-551, 2006.

T. S. Epstein. South India: Yesterday, Today and Tomorrow. Holmes and Meier, New York, 1973.

E. A. Gait. Census of India, 1911, volume 1. Calcutta, 1913.

Jack Goody. Bridewealth and dowry in Africa and Eurasia. In Jack Goody and Stanley J. Tambiah, editors, Bridewealth and Dowry. Cambride University Press, 1973.

Marcia Guttentag and Paul F. Secord. The Sex Ratio Question. Sage Publications, 1983.

J.H. Hutton. Census of India, 1931, volume 1. 1933.

IndiaStat. Annual estimates of birth rate, death rate, natural growth rate, infant mortality rate and total fertility rate by residence in India. webpage, 2009. URL http://www. indiastat.com/table/health/16/others/17832/7731/data. aspx. 
Madhu Kishwar. Beginning with our own lives: a call for dowry boycott. In Srimati Basu, editor, Dowry and Inheritance, chapter 3, pages 265-67. Zed Books, 2006.

Praveena Kodoth. Gender, caste and matchmaking in Kerala: A rationale for dowry. Development and Change, 39(2):263-283, 2008.

Lars Ljungqvist and Thomas J. Sargent. The European unemployment dilemma. Journal of Political Economy, 106(3):514-550, 1998.

Trevon Logan and Raj Arunachalam. Is there dowry inflation in South Asia? NBER Working Paper, (13905), March 2008.

Angus Maddison. A comparison of levels of GDP per capita in developed and developing countries, 1700-1980. The Journal of Economic History, 43(1):27-41, 1983.

J. T. Marten. Census of India, 1921, volume 1. Calcutta, 1923.

Werner Menski, editor. South Asians and the dowry problem. Trentham Books Ltd., 1998.

P. Padmanabha. Census of India, 1971: Mysore, volume 14. 1973.

Rajni Palriwala. Reaffirming the anti-dowry struggle. In Srimati Basu, editor, Dowry and Inheritance, Issues in Contemporary Indian Feminism, chapter 3, pages 279-290. Zed Books, 2006.

Madan Chandra Paul. Dowry and Position of Women in in India: A Study of Delhi metropolis. Inter-India Publications, New Delhi, 1986.

B.D. Prasad. Dowry-related violence: A content analysis of news in selected newspapers. Journal of Comparative Family Studies, 25(1):71-89, 1994.

Indira Rajaraman. The economics of brideprice and dowry. In Srimati Basu, editor, Dowry and Inheritance, chapter 1, pages 42-55. Zed Books, 2006.

Vijayendra Rao. The rising price of husbands: a hedonic analysis of dowry increases in rural India. Journal of Political Economy, 101(4):666-677, 1993.

J.R. Rele. Fertility levels and trends in India, 1951-81. Population and Development Review, 13(3):513-530, 1987.

Anja Sautmann. Search, Marriage, and Demographics: The Marriage Squeeze in India and age patterns of marriage. PhD thesis, New York University, 2010. 
T. V. Sekher, K. N. M. Raju, and M. N. Sivakumar. Fertility transition in Karnataka. Economic and Political Weekly, 22:4742-4752, December 2001.

Amartya Sen. Missing women. British Medical Journal, 304(6827):587-588, March 1992.

Aysan Sev'er. Discarded daughter: The patriarchal grip, dowry deaths, sex ratio imbalances and foeticide in India. Women's Health and Urban Life, 7(1):56-75, 2008.

Ursula Sharma. Dowry in North India: Its consequences for women. In Srimati Basu, editor, Dowry and Inheritance, Issues in Contemporary Indian Feminism, chapter 1, pages 15-26. Zed Books, London and New York, 2006.

Kumar Suresh Singh. People of India: Maharashtra, volume 30. Anthropological Survey of India, 2004.

S. Sivasubramonian. The National Income of India in the Twentieth Century. Oxford University Press, 2000.

Mysore Narasimhachar Srinivas. Religion and Society among the Coorgs of South India. Clarendon Press, Oxford, 1952.

Mysore Narasimhachar Srinivas. Some Reflections on Dowry. J.P. Naik Memorial Lecture. Centre for Women's Development Studies, Delhi, 1984.

Michele Tertilt and Urvi Neelakantan. A note on marriage market clearing. Economic Letters, June 2008.

United Nations. Model Life Tables for Developing Countries. United Nations, 1982.

United Nations. Age Structure and Mortality in Developing Countries. United Nations, 1986.

Pravin M. Visaria. The Sex Ratio of the Population of India. Number Monograph No. 10. Census of India 1961, 1969.

Shang-Jin Wei and Xiaobo Zhang. The competitive saving motive: Evidence from rising sex ratios and savings rates in China. Journal of Political Economy, 119(3):511-564, 2011.

K.C. Zachariah. The anomaly of the fertility decline in India's Kerala State: a field investigation. World Bank, 1984.

Junsen Zhang and William Chan. Dowry and wife's welfare: a theoretical and empirical analysis. Journal of Political Economy, 107(4):786-808, 1999. 